\title{
Employing the theory of planned behaviour to design an e-cigarette education resource for use in secondary schools
}

\author{
E. E. A. Simpson ${ }^{\text {* }}$, J. Davison ${ }^{1}$, J. Doherty², L. Dunwoody ${ }^{1}$, C. McDowell ${ }^{1}$, M. McLaughlin ${ }^{1}$, S. Butter ${ }^{1}$ and \\ M. Giles ${ }^{1}$
}

\begin{abstract}
Background: An extended version of the theory of planned behaviour (TPB) was used to inform the design of a framework for an educational resource around e-cigarette use in young people.

Methods: A sequential exploratory design was employed. In Phase 1, elicited behavioural, normative and control beliefs, via 7 focus groups with 51 participants, aged 11-16years, identified salient beliefs around e-cigarette use. These were used to construct a questionnaire administered to 1511 young people aged 11-16years, which determined predictors of e-cigarette use and ever use. In Phase 2, sociodemographic variables, e-cigarette knowledge, access, use, marketing and purchasing of e-cigarettes and smoking behaviour were also gathered. The composite findings from Phase 1 and 2 informed the design of a post primary educational resource in Phase 3 around e-cigarette use.

Results: Current e-cigarette use was $4 \%$, with almost $23 \%$ reporting ever use, suggesting current use is stable but experimentation may be increasing in this cohort. Sociodemographic variables, knowledge of e-cigarettes, smoking behaviour and TPB variables (direct and indirect measures of attitudes, subjective norm, and perceived behavioural control) accounted for $17 \%$ of the variance in current e-cigarette use, with higher intentions to use e-cigarettes within the next month, having the strongest impact on use $(p<0.001)$, followed by self-efficacy $(p=0.016)$. Sociodemographic and TPB variables accounted for $65 \%$ of the variance in intentions to use e-cigarettes in the next month; current e-cigarette use $(p<0.001)$, more positive attitudes $(p<0.001)$, stronger social influence $(p<0.001)$, higher self-efficacy $(p<0.001)$, higher control beliefs $(p<0.001)$ and greater motivation to use e-cigarettes $(p<0.001)$ were the main predictors of intentions. Phases 1 and 2 informed the mapping of key predictors of intentions and use of e-cigarettes onto the Theoretical Domains Framework, which identified appropriate intervention functions and behaviour change techniques.
\end{abstract}

Conclusions: This paper is the first to bridge the theoretical-practice gap in an area of significant public health importance through the development of a framework for a novel theory driven school-based educational resource aimed at reducing experimentation and uptake of e-cigarette use in young people.

Keywords: E-cigarettes; vaping, Theory of planned behaviour; young people, School-based intervention, Behavioural change taxonomy, Theoretical domains framework

*Correspondence: eea.simpson@ulster.ac.uk

1 School of Psychology, Ulster University, Coleraine, Northern Ireland, UK

Full list of author information is available at the end of the article

(c) The Author(s) 2022. Open Access This article is licensed under a Creative Commons Attribution 4.0 International License, which permits use, sharing, adaptation, distribution and reproduction in any medium or format, as long as you give appropriate credit to the original author(s) and the source, provide a link to the Creative Commons licence, and indicate if changes were made. The images or other third party material in this article are included in the article's Creative Commons licence, unless indicated otherwise in a credit line to the material. If material is not included in the article's Creative Commons licence and your intended use is not permitted by statutory regulation or exceeds the permitted use, you will need to obtain permission directly from the copyright holder. To view a copy of this licence, visit http://creativecommons.org/licenses/by/4.0/. The Creative Commons Public Domain Dedication waiver (http://creativeco mmons.org/publicdomain/zero/1.0/) applies to the data made available in this article, unless otherwise stated in a credit line to the data. 


\section{Introduction}

The use of electronic cigarettes (e-cigarettes) has increased globally in young people $[1,2]$, at a time when traditional forms of smoking are declining [3, 4], and public health messages do not recommend their use in this group [5], hence such trends need to be closely monitored $[1,5,6]$. Although, regular use of e-cigarettes in young people remains low in the UK $[7,8]$ at around $4.9 \%$ in 2019 , and mainly in smokers, experimentation is increasing and reported to be between 8.5 and 20\% [7, 9, $10]$, compared to $16 \%$ experimentation with traditional cigarettes [3].

Adolescents appear to initiate e-cigarette use out of curiosity and their appealing attributes, in that they are "cool" and "less harmful", compared to traditional cigarettes; whereas adults initiate their use mainly to quit smoking [11-14]. Therefore, there is no harm reduction application in e-cigarette use in young people $[15,16]$. More worrying, current research is starting to link e-cigarette experimentation and use with more long-term nicotine addiction and subsequent initiation of smoking $[10,17-22]$, alcohol and drug use [10, 23, 24]. Some of the evidence is US based and may not be directly applicable to the UK due to different controls and regulations around e-cigarette production and control.

Since 2018, the Medicines and Healthcare products Regulatory Agency have set several controls around the sale and nicotine content of e-cigarettes. It is illegal to sell e-cigarettes to anyone under the age of 18 years in the UK, there are restrictions on advertising such products, and the maximum amount of nicotine allowed in an e-cigarette is $20 \mathrm{mg} / \mathrm{ml}$. In comparison to the U.S. which does not have nicotine concentration restrictions and does not allow the sales of e-cigarettes to anyone under the age of 21 years. However, this has not prevented the illegal selling of super strength nicotine e-cigarettes to children in the UK, using social media to advertise such products, and raising concerns about the impact on health by Action on Smoking and Health (ASH, 2021) [25]. Adding to this concern, is the link between e-cigarettes and smoking which may be dose dependent, so the greater amount of nicotine in an e-cigarette the more likely it is to lead to traditional smoking in young people [19] and may be reinforced by the rewarding effects of vaping [26]. This has the potential to undo reduction trends in smoking behaviour in the UK and may have long term implications for health, therefore e-cigarette use in young people needs to be monitored.

The marketing of e-cigarettes may make them more appealing to young people, as they are presented on social media platforms via influencers [27, 28], and may be contributing to global increased use in this age group $[29,30]$. In addition, the variety of devices and customised flavours designed to appeal to younger consumers (milkshake, chocolate, bubble-gum), promote experimentation with e-cigarettes in some studies [28, 31]. There are currently no restrictions on buying e-cigarettes with flavours in the UK, but other European countries are banning flavours, such as the Netherlands, in an attempt to reduce use in young people. More regular use of e-cigarettes in young people is also promoted by ease of purchase, absence of smoke, ease of concealment, parental smoking and lack of legislation controlling purchasing behaviour [13].

Safety concerns have emerged about the contents of some e-cigarettes, which typically include propylene glycol, vegetable glycerine, flavourings, and nicotine [32, 33]. There are over 7000 flavourings that can be added to e-cigarettes, the toxicity of which are unknown $[15$, 34], and some studies report additional harmful chemicals, such as formaldehyde and nickel [35]. It is not surprising that there is emerging evidence suggesting some e-cigarettes have the potential to impact negatively on respiratory, cardiovascular and brain function in adolescents, even with short term use $[1,29,36]$. Such findings make it an urgent public health requirement to better understand predictors of e-cigarette use and identify educational needs around e-cigarette use in schools, in an effort to promote informed choice and prevent uptake in young people [37].

Recommendations from a recent systematic review suggest that e-cigarette prevention and cessation programmes for young people need to be separate from tobacco campaigns and grounded in behaviour change theory $[1,38]$. This need is met in the current study, as the theory of planned behaviour (TPB) $[39,40]$ was employed as the theoretical framework, with the sole focus on e-cigarette use. It is a leading behaviour change theory recognised by National Institute for Health and Care Excellence (NICE) for its effectiveness in the design and evaluation of behaviour change interventions [41, 42]. According to the theory, behaviour is determined by behavioural intentions, which in turn are influenced by three independent constructs, attitudes (advantages and disadvantages of engaging in a behaviour) subjective norms (SN - social influences on the behaviour) and perceived behavioural control (PBC - facilitators and barriers to a behaviour), often separated into measures of perceived control and self-efficacy) $[39,40]$. A small number of recent studies have applied the TPB to e-cigarette use, but there are limitations as to what can be drawn from this work, because these studies are not full TPB applications, they have not followed the sequential framework recommended by Ajzen [39] and Francis et al. [40]. for the design and conduct of TPB studies [43]. The few that have used the ТРВ have done so with adult or 
student populations, with none of this work conducted amongst adolescents [43-45]. Also, many of these studies have only used single items to assess e-cigarette use, i.e. 'Have you ever tried an e-cigarette?' [7], or have been embedded within larger well-being surveys [46]. Our study addressed these limitations and gaps, and enabled identification of targets for intervention development through the design of a theory driven framework for an educational resource to be used in post primary schools. This hascombined theory and practice in an area of significant public health importance in the UK.

\section{Rationale for current study}

The overriding aim of this research project was to assess prevalence and predictors of e-cigarette use and experimentation in young people aged 11-16years in Northern Ireland (NI) Objectives: (1) An elicitation study was conducted to identify factors that influenced young peoples' motivations to use e-cigarettes; (2) a TPB-based questionnaire was constructed from the elicited beliefs; (3) the questionnaire was administered to a representative sample of young people, which determined knowledge, attitudes, prevalence of e-cigarettes use, experimentation, and identified the potential predictors of use (4), this informed the design of an framework for an educational resource to be used in post primary schools, to prevent e-cigarette uptake and experimentation [37, 47]. This will be the first theory driven, evidenced based e-cigarette intervention for young people in the UK, designed to be incorporated into the curriculum [10].

\section{Materials and methods}

Consistent with the advice of Ajzen [39] and Francis et al. [40], a sequential mixed methods design identified the key underlying beliefs around e-cigarette use, which was in keeping with other successful TPB school-based interventions that targeted adolescents [48]. This research was conducted in three Phases. Phase 1: An elicitation study, identified the indirect salient beliefs around e-cigarette use and involved a series of focus groups; Phase 2: A TPB questionnaire survey was based on the most common behavioural beliefs, social influences and control beliefs from Phase 1; Phase 3: Intervention Mapping informed the design of a framework for an educational resource aimed at enhancing young people's intentions not to use e-cigarettes. This was achieved by targeting the major predictors of intentions and use of e-cigarettes, along with the theoretical domains framework and the Behaviour Change Techniques Taxonomy (BCTT), to guide the intervention functions and behaviour change techniques $[49,50]$.

\section{Phase 1: elicitation study \\ Aim}

The aim of this Phase was to explore the salient beliefs that surrounded e-cigarette use in young people, it used qualitative methods and informed the design of a questionnaire based on the most frequently reported beliefs.

\section{Design}

Since young people do not form attitudes towards e-cigarettes in isolation [2], focus group methodology was deemed the most appropriate method to capture the dominant beliefs within this cohort. This allowed the researcher to experience the dynamics of the group as well as the practicalities and the sensitivities surrounding the target behaviour [51]. Further, such qualitative work enhanced the validity of questionnaires developed from their findings [52], which informed the basis of Phase 2 of this research.

\section{Participants and procedure}

Following ethical approval from the Ulster University Research Ethics Committee (UREC), data were collected during December 2016. A sample of post primary schools from each of the five Education Authority (EA) areas in NI was sought, and included children from different socio-economic groups, as well as schools in receipt of free school meals (FSM) (a social indicator of deprivation; Education Authority for NI, 2009 [53]. Contact was initially made with five post primary schools, and invitation letters that detailed the study aims, objectives and procedures, were emailed to each school, two schools agreeed to participate. The schools were asked to randomly select one class from each year group (years 8 to 12), and distributed parent and pupil information sheets and consent/assent forms, to all pupils in the selected class. Only those children who had completed parental consent and pupil assent took part in the focus group.

This resulted in seven focus groups, conducted by an experienced facilitator, involving a total of 51 young people aged $11-16$ years (mean age $=13.45$ years $(\mathrm{SD}=1.346)) ; 22$ were male and 29 females. The size of focus groups ranged from 3 to 10 participants, with an average of 7 participants in each group. In keeping with the format specified by Francis et al. [40] and Fishbein \& Aizen, [39], nine open-ended questions were asked. The behaviour of interest (intentions to use e-cigarettes) needed to be clearly defined and specified, this was achieved in accordance with the TPBs TACT principles (Target: 11-16 year olds; Action: e-cigarette Use; Context: Everyday life; and Time: within the next month $[39,40]$. The focus group questions tapped into the main constructs within the 
theory, and elicited accessible beliefs about attitudes (What do you believe are the advantages of using e-cigarettes?), SN (Are there any people or groups who would approve of you using an e-cigarette?) and $\mathrm{PBC}$ (What factors or circumstances would enable you to use e-cigarettes?) factors, questions are given in supplementary data 1 .

Each focus group was conducted using strategies and recommendations by Gibson [54] and lasted approximately 30 to $40 \mathrm{~min}$. At the start of each focus group, the facilitator introduced themselves, explained both the project and the format of the focus group, etiquette around taking turns to speak and welcomed any questions from participants. Participants were also invited to complete a socio-demographic questionnaire (age, gender, mother/father/guardian was in employment), and questions on smoking and e-cigarette use. The session then began with an introductory conversation about e-cigarettes, participants were asked if they had heard of e-cigarettes or seen them advertised. This helped to ensure that participants were relaxed and aided group dynamics, as it offered individuals the opportunity to speak and contribute to the discussions. All opinions were welcomed and respected. Data saturation was achieved (i.e. no new data or themes emerged), which suggested an adequate sample was reached [55]. All focus groups were audio recorded and transcribed verbatim.

\section{Data analyses}

Data were content analysed [56] and organised into emerging behavioural, normative and control beliefs in keeping with the TPB manual and Aizen's recommendations $[39,40]$. This was achieved by reading the transcripts several times, becoming familiar with their contents, coding the data, and identifying patterns in the data, which led to subthemes being established and labelled. This process was completed by two independent researchers who compared and discussed beliefs until a consensus was reached. The themes (Table 1) represented the "modal salient beliefs" of this cohort, also called the indirect beliefs about e-cigarettes, and were used to inform the construction of the TPB questionnaire. This involved a summative analysis of the themes to determine the order of frequency of beliefs within each construct [40], the most frequently occurring themes were included and used to formulate the belief-based (direct beliefs) measures of attitudes, SN and $\mathrm{PBC}$ that were used in the questionnaire, which required further investigation in a larger scale survey in Phase 2.. This purposeful approach to counting is recognised as good practice in qualitative research [57].

\section{Results}

All TPB constructs were reported to be relevant to e-cigarette use, see Table 1 for an overview of themes and sample quotes. Participants held attitudes about the advantages and disadvantages of using e-cigarettes. Contradictory views were discussed in relation to the health impact and potential as a quitting device. Of significance was the appeal of e-cigarettes amongst this cohort, as they were viewed as 'cool' and 'stylish to use.' The ease with which e-cigarettes were obtained and the variety of flavours were also considered factors that encouraged experimentation and use. Participants were aware that it was illegal for them to purchase or use e-cigarettes, but their accessibility and provision from friends and parents greatly encouraged usage. When asked about the importance of significant others in relation to e-cigarette use, specific reference was made to friends and family, parents who were viewed as both approving and disapproving of their use. Participants reported they were less likely to get into trouble with parents if caught with an e-cigarette, as their parents perceived them to be less harmful in comparison to traditional cigarettes. The strong social influence from friends encouraged and facilitated e-cigarette use in social contexts, by borrowing friends' devices or coming under peer pressure to use them. E-cigarettes were also regarded as being more convenient to use given that there were fewer restrictions placed on where they could be used, in addition to them being easy to carry in their pockets. The expense of purchasing the vaping device, as well as safety concerns surrounding the actual device (exploding batteries) were however viewed as factors that discouraged their use.

\section{Phase 2: questionnaire survey \\ Aim}

The aim of this Phase was to continue the formative components of the research and developed a TPB questionnaire, based on the findings of Phase 1 . This allowed the identification of the most significant predictors surrounding e-cigarette use and experimentation in young people aged 11-16years, it informed which beliefs should be targeted to change intentions and behaviour and informed the design of an educational resource described in Phase 3 [58]. This was achieved by administering the TPB based questionnaire formulated from the salient beliefs elicited from Phase 1 of the study (Table 2).

\section{Design}

In keeping with TPB protocols, the TPB questionnaire included direct measures of attitudes, SN, PBC and intentions and behaviour [40]. Also, the indirect measures included behavioural beliefs and outcome evaluations, normative beliefs, and motivation to comply and control 
Table 1 Thematic analysis showing beliefs elicited and quotes from the focus group data about E-cigarette use in 11-16year olds

\begin{tabular}{|c|c|c|}
\hline Component & Theme & Example Quotation \\
\hline \multirow[t]{5}{*}{ Attitude } & Health & $\begin{array}{l}\text { 'It's better than smoking... there's no like rocket fuel in them and all that, you know those other things that give you } \\
\text { cancer and stuff...' } \\
\text { 'They are still harmful; you are still smoking. You are inhaling something into your body so they are still affecting your } \\
\text { lungs.' } \\
\text { 'You probably get addicted to them with nicotine in it.' }\end{array}$ \\
\hline & Cessation & $\begin{array}{l}\text { 'I think they are good cause they stop you smoking.' } \\
\text { 'It could take you off them (cigarettes) for a while. They are good cause they help you quit smoking' } \\
\text { 'People use them to try to get off cigarettes. }\end{array}$ \\
\hline & Cost & $\begin{array}{l}\text { 'Price is really the worst thing like, I've just spent sixty quid on a new one yesterday'. } \\
\text { 'Yeah, like they are all using e-cigarettes cause they can't afford cigarettes now'. } \\
\text { 'Some of them are really expensive...' }\end{array}$ \\
\hline & Appeal & $\begin{array}{l}\text { 'There's no smell like when you smoke an e-cigarette like the smell doesn't stick to you'. } \\
\text { 'It's just it's fun... they are nice tasting... there are lots of nice flavours.' } \\
\text { 'You can blow hoops like the wee kind of tricks you can do.' } \\
\text { 'Ijust think they are class looking.' } \\
\text { 'They are stylish to have.' }\end{array}$ \\
\hline & Safety & $\begin{array}{l}\text { 'You don't know if it will explode when it's charging... it could catch fire... some of them blow up in your face'. } \\
\text { 'You don't really know what's in them. Some places might have their own house flavours.. you don't know what's in } \\
\text { them.' } \\
\text { 'They wouldn't burn your house down like can happen with cigarettes.' }\end{array}$ \\
\hline \multirow[t]{5}{*}{ Subjective Norms } & Parents & $\begin{array}{l}\text { 'My mum would want me to use one.' } \\
\text { 'Because they (parents) are trying to give you the best advice to keep yourself healthy.' } \\
\text { 'they (parents) probably wouldn't care if you'd an e-cigarette, but they care more if you've cigarettes' }\end{array}$ \\
\hline & Family & 'Probably my uncle cause he, his children and stuff all do it'. \\
\hline & Friends & $\begin{array}{l}\text { 'Friends want you to do what they are doing....' } \\
\text { 'If your friends are using them.. .you are able to use theirs.' }\end{array}$ \\
\hline & Teachers & $\begin{array}{l}\text { 'Teachers cause they're looking you to represent the school well and all that'. } \\
\text { "I guess teachers, I don't think they would like us to use them". }\end{array}$ \\
\hline & $\begin{array}{l}\text { Other profes- } \\
\text { sionals e.g. } \\
\text { coaches }\end{array}$ & $\begin{array}{l}\text { "Probably like, the doctors, or like the dentists cause like your teeth are going to rot if you smoke". } \\
\text { "Yeah, .... doctors". }\end{array}$ \\
\hline \multirow[t]{6}{*}{$\begin{array}{l}\text { Perceived Behav- } \\
\text { ioural Control }\end{array}$} & Peer Pressure & $\begin{array}{l}\text { 'it's a social thing, if everyone else is doing it as well..' } \\
\text { 'Kind of just want to fit in.' } \\
\text { 'The ides of fitting in, like peer pressure..' }\end{array}$ \\
\hline & Perception & $\begin{array}{l}\text { 'Some people think they're stylish to use'. } \\
\text { 'Ijust think they are class looking.' } \\
\text { 'Yeah it looks pretty cool.' } \\
\text { '... yeah cause you can get ones in really nice colours and stuff...' }\end{array}$ \\
\hline & Conformity & $\begin{array}{l}\text { 'If you are caught with it by your mum or dad or whatever its less serious than being caught with cigarettes.' } \\
\text { 'If your parents allowed you to have one...' } \\
\text { 'The law would prevent us using them... if you are our age you're not allowed to use one... the government don't allow } \\
\text { us to use them'. } \\
\text { 'We aren't allowed to use them... it's the law, we can't buy them...' }\end{array}$ \\
\hline & Availability & $\begin{array}{l}\text { 'If your parents have one then you can use theirs.' } \\
\text { 'Getting one as we aren't allowed to buy them.' } \\
\text { 'If your friends are using them... you are able to use theirs.' }\end{array}$ \\
\hline & Convenience & $\begin{array}{l}\text { 'You can just whip it out and smoke it anywhere.' } \\
\text { 'It kind of saves you having to carry around cigarettes and lighters.' } \\
\text { 'Easy to carry around, you can't carry a cigarette around as it would burn a hole in your pocket. }\end{array}$ \\
\hline & Curiosity & $\begin{array}{l}\text { 'Just wanting to do it. Wanting to try it... to try something new.' } \\
\text { 'Just something to fill your time.' } \\
\text { 'Just to try it...' }\end{array}$ \\
\hline
\end{tabular}

$N=51$

beliefs and perceived power to influence behaviour, all for attitude, SN and PBC. In addition to TPB constructs, based on the salient beliefs' items identified in Phase 1 
Table 2 Salient beliefs elicited about e-cigarette use

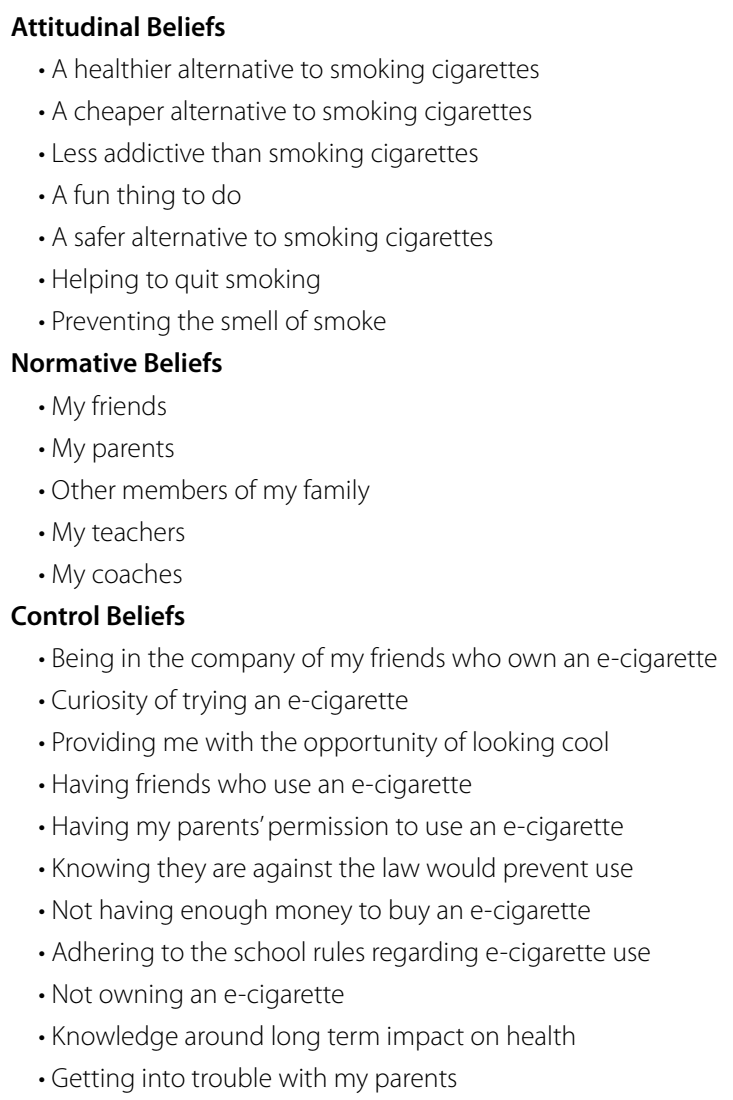

other variables relevant to the target behaviour were also included in the questionnaire (Table 3 ).

\section{Participants and procedure}

The survey was undertaken between January 2018-January 2019. All post primary schools in NI were informed of the study objectives, via email and invited to participate. Ten percent of schools $(N=21)$ took part, which is similar to previous TPB research [48], and a financial incentive (£250) was given to each participating school.

Participants aged 11-16years, both male and female, smokers and non-smokers, users and non-users of e-cigarettes were recruited from one randomly selected class from each year group (years 8-12), within each school, and provided a sample of 5 classes from each school. Each child received a study pack (an invitation letter, Participant Information Sheet, Consent form) to take home for one parent to complete. Those children who had parental consent and gave their assent on the day of testing, attended a room within the school and completed the questionnaire. The researcher was available during completion to support students and answer any questions.
The final sample comprised 1511 pupils, aged 11-16 years, across 21 secondary schools in NI, with a mean age of 13.5 years (Table 4 ). Just over half were female and from grammar schools, with all year groups (8-12) represented. A representative sample of all school types was achieved (i.e. grammar schools, secondary and integrated schools), with a mixture of management type ( $n=7$ were voluntary Grammar schools; $n=9$ were state maintained schools; $n=2$ grant maintained schools and $n=3$ were Council for Catholic Maintained Schools), single sex $(n=3)$ and co-educational $(n=18)$.

\section{Questionnaire}

The questionnaire consisted of five sections: 1) background information (see variables in Table 4); 2) e-cigarette use (past use, current use, parental use, exposure to advertising and marketing of e-cigarettes); 3) the predictors of e-cigarette use, using direct and belief-based measures of the TPB; 4) knowledge of e-cigarette; 5) to determine smoking behaviour (never smokers, experimenters, and occasional or regular smokers) and cessation. The TPB questionnaire was designed and scored in keeping with the TPB manual [48]. Table 3 provides 
Table 3 TPB questionnaire items and alpha reliabilities

\begin{tabular}{|c|c|c|}
\hline Construct & $\begin{array}{l}\text { Number } \\
\text { of items }\end{array}$ & Sample items \\
\hline Intention & 3 & $\begin{array}{l}\text { I intend (want to/going to) use an e-cigarette within the next month; (5) strongly agree (1) strongly } \\
\text { disagree (Cronbach's } a=0.97) \text {. }\end{array}$ \\
\hline \multirow[t]{2}{*}{ Attitude } & 4 & $\begin{array}{l}\text { Direct attitude: } \\
\text { For me, using an e-cigarette within the next month would be very healthy (5)/very unhealthy ( } 1 \text { ); very } \\
\text { good (5)/very bad (1); very foolish (1)/ very wise (5). (Cronbach's } a=0.89) \text {. }\end{array}$ \\
\hline & 8 & $\begin{array}{l}\text { Indirect 'belief-based'attitude: } \\
\text { Seven outcome evaluations (See Table 2), e.g. 'safer alternative to cigarettes': very good (+ 2) to very } \\
\text { bad ( }-2 \text { ) multiplied by the corresponding behavioural belief, e.g. 'using an e-cigarette would be a } \\
\text { safer alternative to cigarettes': very true (5) to very untrue (1). }\end{array}$ \\
\hline \multirow[t]{2}{*}{ Subjective Norm } & 4 & $\begin{array}{l}\text { Direct subjective norm: } \\
\text { Most people who are important to me think that I should (would approve/would want me to) use an } \\
\text { e-cigarette: 'strongly agree' (5) to strongly disagree (1). (Cronbach's } a=0.67 \text { ). }\end{array}$ \\
\hline & 6 & $\begin{array}{l}\text { Indirect subjective norm: } \\
\text { Six normative beliefs (See Table } 2) \text { e.g.'my parents think that I should use an e-cigarette': strongly } \\
\text { agree }(+2) \text { to strongly disagree }(-2) \text { multiplied by the corresponding motivation to comply e.g.' gen- } \\
\text { erally speaking I want to do what my parents want me to do': strongly agree (5) to strongly disagree } \\
\text { (1). }\end{array}$ \\
\hline \multirow[t]{2}{*}{ Perceived Behavioural Control } & 3 & $\begin{array}{l}\text { Direct perceived behavioural control: } \\
\text { Whether I use an e-cigarette or not is entirely up to me: strongly agree (5) to strongly disagree (1); It is } \\
\text { mostly up to me whether I use an e-cigarette or not: strongly agree (5) to strongly disagree (1); It is my } \\
\text { decision whether I use an e-cigarette or not: strongly agree (5) to strongly disagree (1). (Cronbach's } \\
a=0.82 \text { ). }\end{array}$ \\
\hline & 11 & $\begin{array}{l}\text { Indirect perceived behavioural control: } \\
\text { Eleven control beliefs (See Table 2) e.g. The curiosity of trying an e-cigarette would encourage me to } \\
\text { use an e-cigarette: very true (5) to very untrue (1)/ Adhering to the law would prevent me from using } \\
\text { an e-cigarette: very true (1) to very untrue (5). }\end{array}$ \\
\hline Self-efficacy & 3 & $\begin{array}{l}\text { Direct self-efficacy } \\
\text { I am confident that I could/I am sure that I could/It is easy for me to use an e-cigarette: strongly agree } \\
\text { (5) to strongly disagree }(1) \text {. (Cronbach's } a=0.89) \text {. }\end{array}$ \\
\hline Knowledge of e-cigarettes & 7 & $\begin{array}{l}\text { The legal age to purchase an e-cigarette is } 18 \text { years/ E-cigarettes do not contain nicotine/E-cigarettes } \\
\text { do not produce tar and carbon monoxide: True/False }\end{array}$ \\
\hline E-cigarettes use & 16 & $\begin{array}{l}\text { Do you/your mother/your father/your care giver use/ever used e-cigarettes Yes/No } \\
\text { How often do you/did you use e-cigarettes (Occasionally, but not every day/1-2 times per week/3-4 } \\
\text { times per week/Only on days that I am/was at school/everyday/weekends only) }\end{array}$ \\
\hline Advertising/Exposure to e-cigarettes & 3 & $\begin{array}{l}\text { Where did you first hear about or see e-cigarettes? Where have you seen e-cigarettes advertised? } \\
\text { Have you been taught about e-cigarettes in school? }\end{array}$ \\
\hline Smoking & 4 & $\begin{array}{l}\text { Do you/your mother/father/care giver smoke tobacco cigarette: Yes/No } \\
\text { How often do you smoke: Everyday/1-2 times per week/3-4 times per week/only the days I am at } \\
\text { school/weekends only }\end{array}$ \\
\hline
\end{tabular}

information on the number of items included in each subscale, with sample questions and Likert answer formats employed for both direct and indirect measures. Intentions were scored by calculating the mean of the item scores. The direct measures of attitudes, SN and PBC: negatively worded items were recoded so that higher scores reflected more positive attitudes, greater social influence, and greater control respectively, then a mean of the item scores was calculated for each subscale. Indirect measures were calculated as follows: each behavioural, subjective norm and control beliefs were scored 1 to 5 , each was multiplied by the relevant evaluation, compliance and power scale items (scored -2 to +2 ). The products were summed for subscale scores.
The internal reliability of each direct scale was calculated using Cronbach's alpha and are presented in Table 3. The questions in sections $1,2,4$ and 5 of the questionnaires were informed by a multidisciplinary Research Advisory Group (RAG) and a User Advisory Group (UAG). The RAG comprised key stakeholders, academics, researchers, public health professionals and policy makers. Whereas the UAG was made up of pupils, teachers, and parents. Both groups were involved in informing all aspects of the study, recommended as being good practice in intervention design [58]. The questionnaire was piloted on a sample of school children who had participated in the elicitation study, this was to check face validity of the questions and ensured that there were no issues 
Table 4 Sociodemographic, school variables and EC use in young people aged 11-16years

\begin{tabular}{|c|c|}
\hline Variable & $\% / M(S D)$ \\
\hline \multicolumn{2}{|l|}{ Pupil information } \\
\hline \multicolumn{2}{|l|}{ Sex \%: } \\
\hline Males & $38 \%$ \\
\hline Females & $59 \%$ \\
\hline Other/ Prefer not to say & $3 \%$ \\
\hline \multicolumn{2}{|l|}{ Age in years: } \\
\hline Mean (SD) & $13.5(1.5)$ \\
\hline \multicolumn{2}{|l|}{ E-cigarette information \%: } \\
\hline E-cigarette users & $4 \%$ \\
\hline Ever use & $22 \%$ \\
\hline \multicolumn{2}{|l|}{ Parent information } \\
\hline \multicolumn{2}{|c|}{ Parental/guardian use of e-cigarettes: } \\
\hline Mother/female guardian & $8 \%$ \\
\hline Father/male guardian & $8 \%$ \\
\hline \multicolumn{2}{|l|}{ In employment: } \\
\hline Mother & $81 \%$ \\
\hline Father & $90 \%$ \\
\hline \multicolumn{2}{|l|}{ School information: } \\
\hline \multicolumn{2}{|l|}{ School type: } \\
\hline Secondary & $33 \%$ \\
\hline Grammar & $59 \%$ \\
\hline Integrated & $8 \%$ \\
\hline \multicolumn{2}{|l|}{ School year: } \\
\hline Year 8 (11-12yrs) & $20 \%$ \\
\hline Year 9 (12-13yrs) & $26 \%$ \\
\hline Year 10 (13-14yrs) & $18 \%$ \\
\hline Year 11 (14-15yrs) & $18 \%$ \\
\hline Year 12 (15-16yrs) & $18 \%$ \\
\hline
\end{tabular}

N 1511, EC Electronic cigarettes

or problems with the items. No subsequent changes were made to the questionnaire, so the pilot sample were included in the survey, in keeping with the TPB manual [40].

\section{Statistical analyses}

Data were analysed using SPSS version 25, checked for normality [59]. The internal reliably of the TPB scales were assessed by Cronbach's alpha [60]. All internal reliabilities for the direct TPB measures were within an acceptable range: intentions $(\alpha=0.97)$, attitudes $(\alpha=0.89)$, SN $(\alpha=0.67)$, PBC $(\alpha=0.82)$, self-efficacy $(\alpha=0.89)$ and were in line with previous research [61, $62]$ that recommended above .5 for alpha reliabilities of subscales [40,63]. Pearson's bivariate correlations were computed prior to conducting the regression analyses to ensure that variables were not highly correlated. To determine predictors of current e-cigarette use, a hierarchical logistic regression analysis was conducted with current e-cigarette use as the dependent variable. The predictors were entered in five steps, with each step controlling for the variables in the previous step. Step one included all sociodemographic and school variables (sex, school year and type (grammar/secondary), mother/female guardian and fathers/ male guardian use of e-cigarettes. In step two, knowledge of e-cigarettes was added; in step three the direct TPB beliefs (direct measures of attitude, SN, self-efficacy and $\mathrm{PBC}$ ), and intentions in step four, with indirect TPB beliefs of attitude, $\mathrm{SN}$, control beliefs in step five. To determine predictors of intentions to use e-cigarettes in the next month a hierarchical linear regression analysis was carried out with intentions to use as the dependent variable. The predictors were entered in six steps. Step one included sociodemographic and school variables; father and mothers e-cigarette use were entered in step two; current pupil e-cigarette use in step 3; knowledge of e-cigarettes was added in step four; step five included the addition of direct measures of the TPB constructs, and the indirect TPB beliefs in the sixth step. Checks on multicollinearity were performed for all hierarchical regression analyses, using collinearity diagnostics, two values were given, tolerance and VIF (variance inflation factor), both of which were within the acceptable values of greater than 0.1 and less than 10 respectively. The contribution of variables in the final step of the regression were examined, significant beta values reported and the semi-partial correlation squared $\left(\mathrm{SPC}^{2}\right)$, which examined the unique contribution of the individual predictor to the overall variance in the predicted variable [64].

\section{Results}

Prevalence of e-cigarette use and experimentation

Over one fifth of the total sample (22.8\%) reported ever having used an e-cigarette; $4.2 \%$ were current users and claimed to use e-cigarettes daily or several times per week. Around 7\% agreed or strongly agreed that they intended to try e-cigarettes within the next month. Around $75 \%$ of users began to experiment with e-cigarettes between the ages of 12-14years and for a small minority (1.6\%), initiation began at the age of 10 . Current and past use of e-cigarettes was higher among males (5.4 and $21.1 \%$ ) than females (2.8 and 16.6\%), although the association between gender and e-cigarette use was not significant. Interestingly, current and past use was highest amongst those who chose to describe themselves as 'other' in response to gender (1.3\%); $15 \%$ of this group reported to be current users and 35\% had experimented with e-cigarettes at some time in the past. E-cigarette use was more common among secondary compared to grammar school pupils. The association here was significant 
$\left(\chi^{2}=16.55, \mathrm{df}=2, p<0.01\right)$, with the former accommodating 5.5 and $22.5 \%$ of current and past users respectively, compared to 3.4 and $15.8 \%$ in the grammar school system. There were no differences between current users in those schools with high and low deprivation indicators (4.2 and 4.5\%), 25\% of those attending schools with high level of FSM reported to be past users compared to $17.4 \%$ in schools with less than $30 \%$ of pupils in receipt of free school meals. The association here was significant $\left(x^{2}=7.44, \mathrm{df}=2, P<0.05\right)$.

Tobacco smoking and e-cigarette use and experimentation Of those sampled, 3.5\% reported that they currently smoked cigarettes. Of these, over half (56.6\%) were currently using e-cigarettes and $30.2 \%$ had experimented with e-cigarettes in the past, meaning that only $13 \%$ of smokers had never tried e-cigarettes. Non-smokers were less likely to use e-cigarettes with $2.2 \%$ reporting to be regular users and $18 \%$ declaring to have tried e-cigarettes at some time in the past. The association between smoking and e-cigarette use was significant, such that smokers were more likely to use e-cigarettes $\left(\chi^{2}=12.85, \mathrm{df}=4\right.$, $p<0.05)$.

E-cigarette use amongst young people was also associated with the behaviour of their parents. Specifically, $10.2 \%$ of young people with a mother/female guardian who used e-cigarettes were current users compared to $3.7 \%$ of those whose mother/female guardian did not use e-cigarettes. Similarly, $29.7 \%$ of young people whose mother/female guardian were users had previously experimented with e-cigarettes compared to $17.6 \%$ whose mother/female guardian were not. These associations were significant $\left(\chi^{2}=24.17, \mathrm{df}=2, P<0.001\right)$. Whilst the percentage differences were not significant for those whose fathers/male guardians used e-cigarettes, young people with fathers/male guardians who used e-cigarettes were more likely to be current users $(7.3 \%$ compared to $4.0 \%$ ) or to have experimented with e-cigarettes in the past (30.1\% compared to $17.4 \%$ ).

\section{Knowledge of e-cigarettes}

Most respondents believed that e-cigarettes were addictive $(85.6 \%)$, that they contain nicotine $(76.9 \%)$, that the legal age of purchase was 18 years $(78.8 \%)$ and that they were cheaper than cigarettes (67.7\%). Approximately two thirds (64.9\%) believed that e-cigarettes were an effective smoking cessation tool. However, respondents were less sure as to the by-products produced by e-cigarettes, less than half endorsed the claim that e-cigarettes produced tar and carbon monoxide (48.2\%). Only a third of individuals believed that e-cigarettes were less harmful than cigarettes containing tobacco (34.6\%).

\section{Marketing and purchasing of e-cigarettes}

Less than $1 \%$ of the sample $(0.7 \%)$ endorsed never having heard about or seen e-cigarettes. Approximately twothirds of the sample reported having first heard about or seen e-cigarettes via strangers using them (68.1\%). This was followed by over a third of the sample endorsing they had seen them in the media $(41.1 \%)$, promotional posters $(40.3 \%)$, the internet $(37.6 \%)$, friends using them $(34.5 \%)$ and social media (34.1\%). Having first seen or heard about e-cigarettes through friends $(24.3 \%)$ and seeing family members using them $(26.9 \%)$ were reported by around a quarter of the sample. A much smaller proportion of individuals reported first seeing or hearing about e-cigarettes through being told about them by family members $(14.0 \%)$, being told about them by health professionals (5.4\%) and other sources (3.1\%).

The vast majority reported getting the device from a friend (54.5\%). Around a tenth reported getting them from a family member or from home (10.5\%), while smaller proportions reported buying them from shops $(3.8 \%)$ or online $(1.7 \%)$. Most individuals reported getting the e-cigarette top-up liquid from a friend (31.2\%) rather than at shops $(5.8 \%)$, family/home $(5.2 \%)$ or online (1.5\%).

\section{Predicting intentions to use e-cigarettes}

Prior to conducting the regression analyses, a series of Pearson's bivariate correlations were calculated for users and non-users, the results of which are displayed in Table 5, these showed small to medium correlations in the expected direction for the TPB constructs. To further explore these relationships, a hierarchical linear regression analysis was carried out with intentions to use e-cigarettes in the next month, as the criterion variable. The predictor variables were entered in six steps, see Table 6 for an overview of the findings at each step. In step one of the model, socio-demographic and school variables were predictive of intentions to e-cigarettes use, accounting for just over $7 \%$ of the variance in the $\mathrm{R}^{2}$; a significant change in the $R^{2}$ occurred with the addition of father and mothers' e-cigarettes use in step two accounting for $9 \%$ of the variance; in step three the addition of current pupil e-cigarettes use, accounted for almost $30 \%$ of the variance, but no change in the $\mathrm{R}^{2}$ with the addition of knowledge of e-cigarettes in step four. Step five included direct measures of the TPB constructs and led to a further increase in the $\mathrm{R}^{2}$, accounting for $57 \%$ of the variance; with the addition of the indirect TPB beliefs in the final sixth step, the variance in intentions explained increased to $65 \%$. The unique contribution of variables to intentions in the final model was assessed by the square of the semi-partial correlation $\left(\mathrm{spc}^{2}\right)$. In terms of the unique 
Table 5 The relationships between TPB variables and knowledge of e-cigarettes in current users and non-users, aged 11-16years

\begin{tabular}{|c|c|c|c|c|c|c|}
\hline & Intentions & Attitude & Subjective Norm & Self-efficacy & PBC & Knowledge of EC \\
\hline \multicolumn{7}{|l|}{ Current users of EC } \\
\hline Intentions & 1 & $0.550^{\mathrm{a}}$ & 0.180 & $0.418^{\mathrm{a}}$ & 0.128 & 0.036 \\
\hline Attitude & & 1 & 0.212 & $0.323^{b}$ & 0.175 & 0.067 \\
\hline Subjective Norm & & & 1 & -0.039 & -0.099 & 0.082 \\
\hline Self-efficacy & & & & 1 & $0.470^{\mathrm{a}}$ & 0.198 \\
\hline PBC & & & & & 1 & 0.108 \\
\hline Knowledge of EC & & & & & & 1 \\
\hline \multicolumn{7}{|l|}{ Non EC users } \\
\hline Intention & 1 & $0.577^{\mathrm{a}}$ & $0.514^{\mathrm{a}}$ & $0.487^{\mathrm{a}}$ & $0.191^{\mathrm{a}}$ & $0.079^{\mathrm{a}}$ \\
\hline Attitude & & 1 & $0.483^{\mathrm{a}}$ & $0.481^{\mathrm{a}}$ & $0.208^{\mathrm{a}}$ & $0.150^{\mathrm{a}}$ \\
\hline Subjective Norm & & & 1 & $0.382^{\mathrm{a}}$ & $0.113^{a}$ & $0.096^{\mathrm{a}}$ \\
\hline Self-efficacy & & & & 1 & $0.487^{a}$ & $0.092^{\mathrm{a}}$ \\
\hline PBC & & & & & 1 & 0.040 \\
\hline Knowledge of EC & & & & & & 1 \\
\hline
\end{tabular}

N 64, ${ }^{\mathrm{a} C}$ Correlation is significant at the 0.01 level (2-tailed). ${ }^{\mathrm{b}}$ Correlation is significant at the 0.05 level (2-tailed). EC Electronic cigarettes, $P B C$ Perceived behavioural control

contribution to variability in intentions in the final model, the only predictors were attitude $\left(\mathrm{spc}^{2}=0.041\right)$, $\mathrm{SN}\left(\mathrm{spc}^{2}=0.012\right)$, self-efficacy $\left(\mathrm{spc}^{2}=0.016\right)$, and control beliefs $\left(\mathrm{spc}^{2}=0.142\right)$, motivation to comply $\left(\mathrm{spc}^{2}=0.029\right)$ and current e-cigarettes use $\left(\mathrm{spc}^{2}=0.11\right)$. These results indicated that higher intention to use e-cigarettes in the next month was predicted by current e-cigarette use $(\beta=1.114, p<0.001)$, having more positive attitudes to

Table 6 Summary of hierarchical linear regression analyses with socio-demographic, school variables, pupil, parent/guardian e-cigarette use, knowledge, direct and indirect TPB variables as predictors of intentions to use e-cigarettes in young people aged 11-16years

\begin{tabular}{|c|c|c|c|c|}
\hline Step & Predictor variables & $R^{2}$ & $\Delta R^{2}$ & $F, d f$ and $p$ \\
\hline 1 & $\begin{array}{l}\text { Socio-demographic } \\
\text { variables - sex, school } \\
\text { year and type }\end{array}$ & 0.076 & 0.076 & $\mathrm{~F}^{(8,1386)}=14.22,<0.001$ \\
\hline 2 & $\begin{array}{l}\text { Mothers/female } \\
\text { guardian and fathers } \\
\text { male guardian EC use }\end{array}$ & 0.097 & 0.021 & $\mathrm{~F}^{(2,1384)}=16.41,<0.001$ \\
\hline 3 & Current pupil EC use & 0.295 & 0.197 & $F^{(1,1383)}=386.7,<0.001$ \\
\hline 4 & Knowledge of EC & 0.296 & 0.001 & $\mathrm{~F}^{(1,1382)}=2.76,0.097$ \\
\hline 5 & Direct TPB measures & 0.571 & 0.275 & $\mathrm{~F}^{(4,1378)}=220.7,<0.001$ \\
\hline 6 & Indirect TPB measures & 0.653 & 0.083 & $\mathrm{~F}^{(3,1375)}=109.2,<0.001$ \\
\hline
\end{tabular}

Step one: socio-demographic and school variables (sex, school year and type). Step two included the addition of mother/female guardian and fathers/male guardian e-cigarette use. Step three included pupil current e-cigarette use, step four saw the addition of knowledge about e-cigarettes. Step five included the addition of the direct measures of attitude, subjective norm, self-efficacy and PBC. Step sex the indirect measures of attitude, subjective norm, and control were added After step one, each subsequent step included the variable(s) from the previous step. Significant $(p<0.05)$ increases in $R^{2}$ indicated in bold their use $(\beta=0.215, p<0.001)$, being influenced by others $(\beta=0.147, p<0.001)$, having greater self-efficacy $(\beta=0.094, p<0.001)$ and control beliefs about e-cigarette use $(\beta=0.040, p<0.001)$ and more motivated to use e-cigarettes $(\beta=0.008, p<0.001)$.

\section{Explaining intentions to use e-cigarettes}

In order to acquire a better understanding of why some young people were more likely to use e-cigarettes than others, and to corroborate the findings from the elicitation study, separate linear regression analyses were conducted with intention as the criterion variable for each and the salient beliefs underlying attitude, SN and $\mathrm{PBC}$ as the predictor variables in separate regressions respectively. Attitudinal beliefs accounted for $37 \%$ of the variance in intentions $\left(\mathrm{F}^{(8,1438)}=106.4, p<0.001\right)$, with e-cigarettes being perceived as being more fun to use $\left(\beta=0.138, p<0.001: \mathrm{spc}^{2}=0.18\right)$, cheaper to buy and safer to use than tobacco cigarettes $(\beta=0.054, p<0.001$ : $\left.\mathrm{spc}^{2}=0.033 ; \beta=0.029, p<0.001: \mathrm{spc}^{2}=0.009\right)$ and less likely to get young people into trouble with parents $\left(\beta=0.031, \quad p<0.001: \mathrm{spc}^{2}=0.030\right)$. Normative beliefs accounted for almost $37 \%$ of the variance in intentions $\left(\mathrm{F}^{(6,1456)}=140.8, p<0.001\right)$, with friends encouraging the use of e-cigarettes $\left(\beta=0.090, p<0.001: \mathrm{spc}^{2}=0.099\right)$, followed by family $\left(\beta=0.040, p=0.04: \mathrm{spc}^{2}=0.005\right)$, parents $\left(\beta=0.037, p=0.005: \mathrm{spc}^{2}=0.005\right)$ and medical professionals $\left(\beta=0.037, p<0.001:\right.$ spc $\left.^{2}=0.011\right)$. Control beliefs accounted for just over $54 \%$ of the variance in intentions $\left.\left(\mathrm{F}^{(11,1422}\right)=148.6, p<0.001\right)$, parental permission to use e-cigarettes would facilitate their use $(\beta=0.291, p<0.001$ : $\left.\mathrm{spc}^{2}=0.112\right)$, preventing use as a result of getting into 
trouble with parents for using them $(\beta=0.176, p<0.001$ : $\left.\mathrm{spc}^{2}=0.046\right)$, curiosity to try e-cigarettes would encourage use $\left(\beta=0.112, p<0.001\right.$ : $\left.\mathrm{spc}^{2}=0.018\right)$, owning one would encourage use $\left(\beta=0.083, p<0.001\right.$ : $\left.\operatorname{spc}^{2}=0.012\right)$, when with friends who are using e-cigarettes, this would facilitate use $\left(\beta=0.066, p=0.011: \mathrm{spc}^{2}=0.004\right)$, perceived as being cool to use e-cigarettes would facilitate their use ( $\left.\beta=0.047, p=0.054: \mathrm{spc}^{2}=0.002\right)$, and adhering to the law would prevent their use $(\beta=0.041, p=0.021$ : $\left.\mathrm{spc}^{2}=0.003\right)$. These findings supported the salient beliefs identified through the elicitation study in Phase 1, as being important influences on e-cigarette use.

\section{Predicting current e-cigarette use}

This study provided an opportunity to determine the role played by the TPB constructs in predicting current e-cigarette use, albeit retrospectively. To this end, a hierarchical logistic regression analysis was conducted with current e-cigarette use as the dependent variable, this referred to use of e-cigarettes daily or several times per week. The predictors were entered in five steps, with each step controlling for the variables in the previous step. Step one: sociodemographic and school variables (sex, school year and type (grammar/secondary)) accounted for $2 \%$ of the variance $\left(x^{2}=29.97, \mathrm{df}=8, p<0.001\right)$ in current e-cigarette use. The addition of mother/ female guardian and fathers / male guardian use of e-cigarettes in step two accounted for $3 \%$ of the variance $\left(x^{2}=11.25\right.$, $\mathrm{df}=2, p=0.004)$, knowledge of e-cigarettes was added in step three and did not account for any variance in use $\left(x^{2}=1.30, \mathrm{df}=1, p=0.253\right)$. The direct TPB beliefs (direct measures of attitude, SN, self-efficacy and PBC) and intentions were added in step four, accounted for $16 \%$ of the variance $\left(x^{2}=188.43, \mathrm{df}=5, p<0.001\right)$ and indirect TPB beliefs of attitude, SN, control beliefs did not account for any further variance in e-cigarettes use in step five $\left(\chi^{2}=4.48, \mathrm{df}=3, p=0.214\right)$. In the final step of the model (Table 7), the main predictors of e-cigarette use were intentions $(\beta=1.61, p<0.001)$ and self-efficacy $(\beta=0.91, p=0.016)$, the odds ratios of 5 and 2.48 respectively, showed that as intentions and self-efficacy in e-cigarette use increased, young people were 5 and 2.5 times more likely to use them.

\section{Phase 3: designing a framework for an educational resource on e-cigarettes to be used in schools}

Phase 1 and Phase 2 provided a comprehensive definition of e-cigarette use in young people and outlined the main beliefs that underpinned the cognitive processes involved in the behaviour and identified what needed to change

Table 7 The final step in the hierarchical logistic regression analysis of predictors of current e-cigarette use in young people aged 11-16years

\begin{tabular}{|c|c|c|c|c|c|c|c|c|}
\hline \multirow[b]{2}{*}{ Variables } & \multirow[b]{2}{*}{ B } & \multirow[b]{2}{*}{ S.E. } & \multirow[b]{2}{*}{ Wald } & \multirow[b]{2}{*}{ df } & \multirow[b]{2}{*}{ Sig. } & \multirow[b]{2}{*}{$\operatorname{Exp}(B)$} & \multicolumn{2}{|c|}{$95 \%$ C.I. for $\operatorname{EXP}(B)$} \\
\hline & & & & & & & Lower & Upper \\
\hline Female & -.222 & 1.166 & .036 & 1 & .849 & .801 & .081 & 7.875 \\
\hline Male & -.181 & 1.165 & .024 & 1 & .877 & .834 & .085 & 8.187 \\
\hline Other & -2.259 & 1.647 & 1.881 & 1 & .170 & .104 & .004 & 2.637 \\
\hline Year 8 (11-12yrs) & -.245 & 1.019 & .058 & 1 & .810 & .783 & .106 & 5.767 \\
\hline Year 9 (12-13yrs) & -.621 & .588 & 1.113 & 1 & .291 & .538 & .170 & 1.703 \\
\hline Year 10 (13-14yrs) & 1.247 & .664 & 3.526 & 1 & .060 & 3.480 & .947 & 12.787 \\
\hline Year 11 (14-15yrs) & -.248 & .595 & .174 & 1 & .677 & .780 & .243 & 2.506 \\
\hline School type & .520 & .475 & 1.195 & 1 & .274 & 1.681 & .662 & 4.270 \\
\hline Mother's/female guardian EC use & .299 & .596 & .252 & 1 & .616 & 1.348 & .419 & 4.337 \\
\hline Fathers/male guardian EC use & -1.042 & .573 & 3.310 & 1 & .069 & .353 & .115 & 1.084 \\
\hline EC Knowledge & -.032 & .199 & .025 & 1 & .873 & .969 & .656 & 1.431 \\
\hline SN & -.177 & .404 & .192 & 1 & .661 & .838 & .380 & 1.849 \\
\hline Attitude & .767 & .400 & 3.678 & 1 & .055 & 2.153 & .983 & 4.714 \\
\hline PBC & .009 & .339 & .001 & 1 & .978 & 1.010 & .520 & 1.961 \\
\hline Self-efficacy & .908 & .378 & 5.784 & 1 & .016 & 2.481 & 1.183 & 5.201 \\
\hline Intention & 1.610 & .288 & 31.22 & 1 & .000 & 5.004 & 2.844 & 8.802 \\
\hline Indirect measure of attitude & .001 & .015 & .009 & 1 & .925 & 1.001 & .973 & 1.031 \\
\hline Indirect SN & .029 & .016 & 3.167 & 1 & .075 & 1.029 & .997 & 1.062 \\
\hline Indirect PBC & -.049 & .040 & 1.461 & 1 & .227 & .952 & .880 & 1.031 \\
\hline Constant & -8.127 & 3.966 & 4.199 & 1 & .040 & .000 & & \\
\hline
\end{tabular}


in relation to e-cigarette use. For example, attitudes that e-cigarettes were safer than traditional cigarettes needed to be challenged as e-cigarettes contain nicotine, which is addictive and linked to future cigarette smoking in adolescents [29].

According to Fishbein and Aizen [65], the next step in employing the TPB, involved reviewing the main predictors of intentions or behaviour, identified in Phase 2 , to inform targets for an intervention. While theories like the TPB are helpful in terms of identifying facilitators and barriers to e-cigarette use, they do not specify how to change such predictors, specifically to bring about a change in behaviour [65-67]. In order to guide the behavioural change process [66], the TPB was used with an integrative framework, the Theoretical Domains Framework (TDF) [49]. Hence the main constructs of the $\mathrm{TPB}$, all of which were identified as predictors on intentions to use e-cigarettes, were mapped onto components of the TDF [49]. This identified intervention functions, levers that can optimise change, via empirically supported behaviour change techniques that map to each intervention function [66]. This process of mapping the components of change onto the intervention functions and suitable theory driven BCTs was thought to produce more effective intervention design and behaviour change $[49,68]$, and is currently lacking in e-cigarette interventions for use in young people focusing on prevention of uptake and cessation [38]. This has been described in more detail below.

\section{Aim}

A primary aim of Phase 3 was to design a TPB theory driven framework for an educational resource to discourage uptake and experimentation with e-cigarettes in young people, whilst also facilitating cessation in those already using e-cigarettes.

\section{Design}

Phase 3 focused on the identification of the intervention's functions and suitable BCTs that were included in the educational resource. An overview of this process is given in Table 8.

\section{Procedure}

This section describes the mapping the main TPB predictors of intentions and e-cigarette use, identified in Phase 2 , onto the TDF in order to identify the intervention functions. The main predictors of current e-cigarette use were intentions and self-efficacy; the main predictors of intentions to use e-cigarettes were attitudes, SN and selfefficacy and control beliefs, so these were mapped onto the TDF, (Table 8). These predictor variables mapped onto 6 of the 14 TDF components, intentions, beliefs about consequences, knowledge, social influences, beliefs about capabilities, along with environmental context and resources.

The next step in this process was to identify the pertinent intervention functions that corresponded to the 6 identified TDF components (Table 8), which were education, persuasion, incentivisation, coercion, modelling, restriction, environmental restructuring, enablement, and training. To decide the appropriateness of the intervention functions for use in the school context, the APPEASE criteria (affordability, practicability, effectiveness and cost-effectiveness, acceptability, side-effects/ safety, and equity) was applied to each of the intervention functions in turn, (the outcome can be found in Table 8), to enhance the appropriateness and suitability of the components of the intervention [69]. It was acknowledged that education needed to be included, to allow young people to make more informed decisions about e-cigarette use. Hence information was included about the risks and benefits of e-cigarette use in young people (attitudes), along with increased understanding of social contexts that might facilitate e-cigarette use (SN), and advice on how to avoid or say no to e-cigarettes (SE). Persuasion not to experiment with e-cigarettes was included to reduce intentions to use e-cigarettes (intentions), to hold less favourable attitudes about their use (attitudes) and prevent use in social contexts (SE). Modelling nonuse and resistance to using e-cigarettes was included to facilitate discussions around use, to enhance informed choice, and to raise awareness of the social impact on behaviour and enhance greater controllability and selfefficacy around e-cigarettes use. Restriction around access to e-cigarettes was included in relation to the environment (accessibility and the law - control beliefs), and in social contexts, where significant others were promoting their use (friends and family - SN). The inclusion of environmental restructuring addressed making accessibility to e-cigarettes more difficult for young people, via identified barriers such as, the need for parental permission, along with a ban on purchasing e-cigarettes and their liquids. Enablement was employed to equip young people with the social skills, support, and knowledge to make more informed choices about e-cigarette use and to practice refusal techniques (SE). Incentivisation, coercion and training were considered inappropriate in this context and were not included in the intervention design.

The next step was to select the most appropriate BCTs for each of the intervention functions. Twelve of the theoretical domains within the TDF, and their corresponding intervention functions, have been linked to $59 \mathrm{BCTs}$ from the Behaviour Change Techniques Taxonomy v 1 $[67,70]$ and the Theory Techniques Tool [71]. Previous research identified the most frequently used BCTs to 


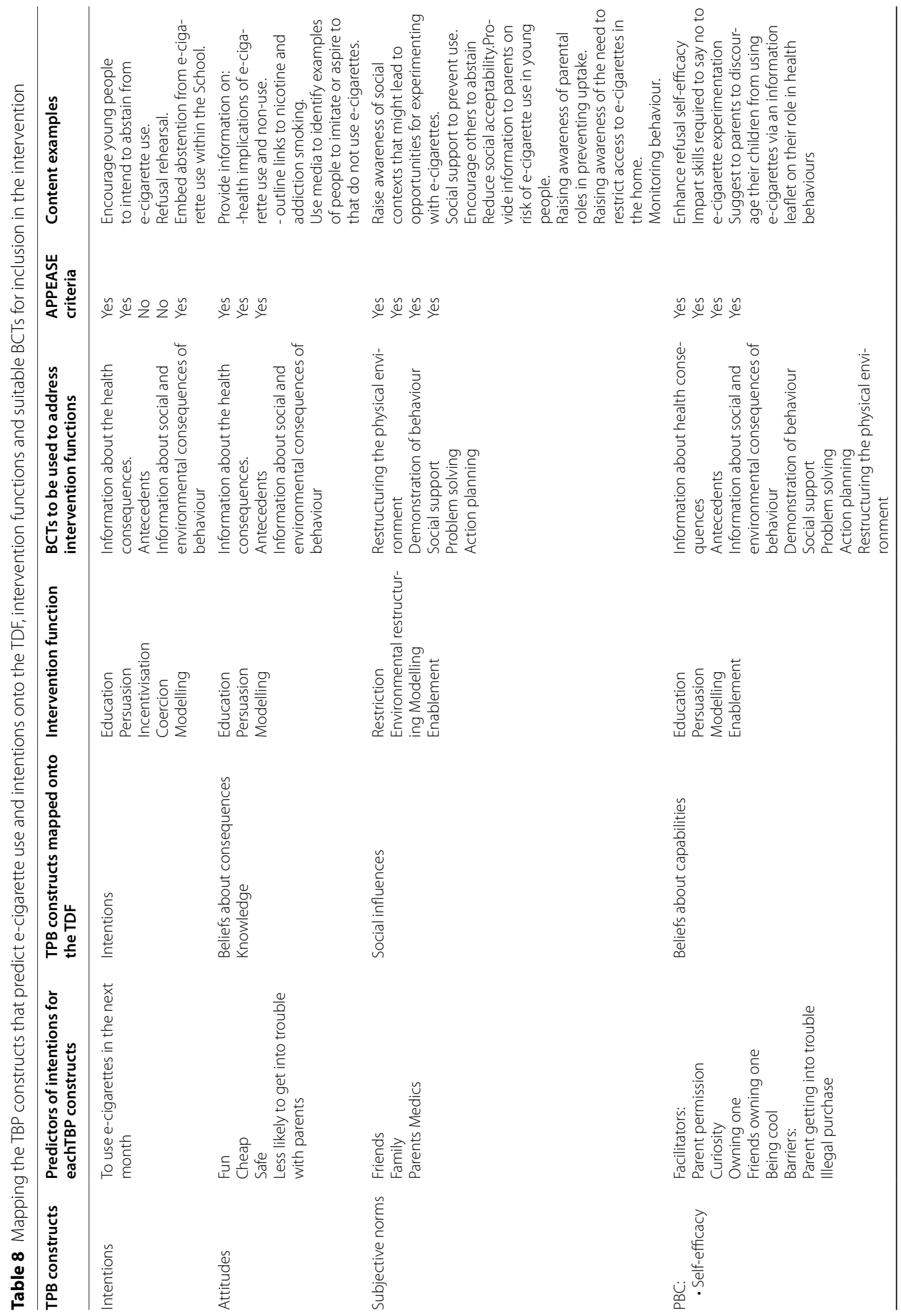




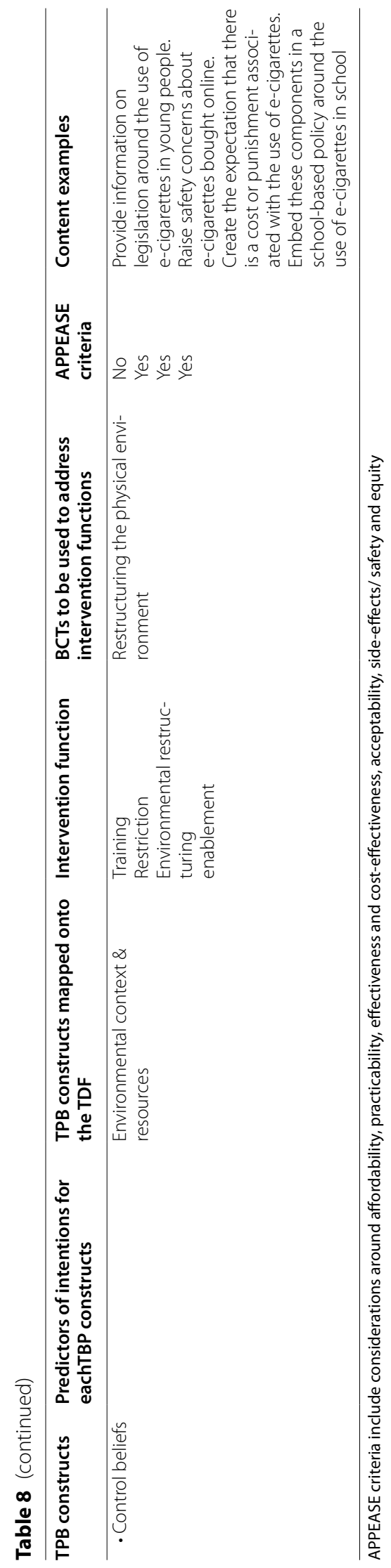


target each intervention function, and empirical evidence to support their effectiveness with regards mechanisms of action [72, 73]. Utilising BCTs provided a standardised description of the components for the framework to make replicable for future studies and has been recognised as good practice in intervention design [70]. Table 8 provides an overview of the BCTs chosen to address the intervention functions and a description of what the framework entails. The content and included BCTs are similar to a recent American intervention that was successful in reducing e-cigarette uptake in middle school pupils, but employed the social cognition model $[74,75]$.

The framework for the educational resource will facilitate co-production of materials with all stakeholders and will consist of a combination of online resources and activities for use in the classroom. For it to be employed successfully and be impactful, it will include a multimodal approach to target young people, their parents, and the school context, such an approach has been employed successfully in previous school-based e-cigarette prevention campaigns in the US [74]. Teachers will need training on how to use the materials correctly and it will include lesson plans, specific sources of information, and group activities for each session. The sessions will target the TPB predictors of behaviour and intentions and should be easily incorporated into the curriculum.

Three lessons for pupils: Firstly, focusing on attitudes, this will include information about the health risks and benefits associated with e-cigarette use, the ingredients in e-cigarettes, the risks of nicotine addiction and gateway to future smoking of traditional cigarettes. Potentially aiming to decrease the positive attitudes surround e-cigarette use, as this has been found to promote initiation of use [76]. Discussion and activities to promote informed choice. Secondly, social influences will be considered through discussion activities considering social situations that might promote experimentation with e-cigarettes. How to manage peer pressure and role play to practice refusal and creating a social context where e-cigarette use is not socially acceptable, this is essential, as social networks of support that promote none-use of e-cigarettes have been found to reduce e-cigarette use in a recent intervention to prevent uptake [74]. Also raising awareness in parents that they have the potential to promote or restrict e-cigarette use in their children. Thirdly, behavioural control will involve discussions around e-cigarette use and the need to abstain from use in young people, promoting a sense of individual control and confidence to refuse e-cigarettes when offered them. This will promote resilience and self-efficacy around abstaining from using e-cigarettes, through discussion and practicing refusal. In addition, raising awareness of the safety and legislation around selling e-cigarettes to young people is important, as it was identified as a barrier to use. Lessons in the classroom focusing on education around e-cigarette use have been successful in changing attitudes, raising the risk of nicotine addiction and reduced intentions to use e-cigarettes $[38,74]$.

Parents are often regarded as active agents of change for the child's behaviour and health [77], for this reason parents need to be educated and informed of the potential part they can play in their child's use and experimentation with e-cigarettes. A health information leaflet will be developed for parents to raise awareness and understanding of the following: the health implications of e-cigarette use in young people; the impact on parental use of e-cigarettes as a facilitator to use in their children; and lastly information on how parents may prevent the uptake of e-cigarettes in their children by setting sanctions for use and creating an environment where it is not acceptable to use them. Parental involvement has been used previously in e-cigarette prevention [74].

Some work is required generally within the school context to help schools make changes to the school ethos and environment around e-cigarette use. To develop school policies and to promote environments where using e-cigarettes are not socially acceptable and come with sanctions. To create a pupil charter where abstaining from using e-cigarettes is agreed with pupils as a key goal. Embedding teaching around e-cigarettes into the curriculum and providing resources to facilitate and support this teaching. Providing visual aids and resources (posters) that are anti e-cigarette use in young people. Providing information and quit signposting for those who want to give up e-cigarettes.

\section{Discussion}

Employing the TPB has provided a more comprehensive understanding of the psychosocial processes involved in e-cigarette use, and intentions to use e-cigarettes, in young people. To our knowledge, this is one of the first TPB studies to use an exploratory sequential design to inform the development of a framework for an educational resource focusing solely on e-cigarettes for use in post primary schools in the UK. This research was conducted in three phrases, Phase 1 and 2 clearly defined e-cigarette use in young people in Northern Ireland and identified underlying factors that mediated current e-cigarette use (intentions and self-efficacy) and intentions to use e-cigarettes (attitudes, SN, self-efficacy, and control beliefs) in this cohort. From the combined results of Phase 1 and Phase 2, which adhered strictly to the recommendations for using the TPB framework $[39,40]$, and in conjunction with the TDF [49], six key intervention functions (education, persuasion, modelling, restriction, environmental 
restructuring, enablement) and eight appropriate $\mathrm{BCTs}$ were identified (information about the health consequences, antecedents to e-cigarette use, information about social and environmental consequences of e-cigarette use, restructuring the physical environment, demonstration of behaviour, social support, problem solving, action planning), for inclusion in the framework for an educational resource in Phase 3. A recent review suggested that e-cigarette prevention and cessation programmes for young people needs to be theory driven, and separate from tobacco campaigns [38], this framework has addressed that gap in the literature.

Phase $1 \& 2$ of this research provided an overview of the extent of current use and experimentation with e-cigarettes in young people in Northern Ireland. Four percent of the sample reported to be regular e-cigarette users, which is comparable to prevalence rates of $4.9 \%$ reported among young people in Great Britain [3] and a slight increase from a separate survey in Northern Ireland of $3 \%$ [78]. In this sample experimentation with e-cigarettes was higher at $22 \%$, compared to recent findings of between 8.5 and $15 \%$ reported in Great Britain $[79,80]$ and may be in line with recent research, which indicates that e-cigarette experimentation across the UK and US has overtaken traditional smoking [81]. In the current study, e-cigarette experimentation, was almost double that reported for tobacco smoking in this age group [7, $46,78]$, and is a worrying statistic. In addition, over $20 \%$ of non-smokers reported that they were current or past users of e-cigarettes, and supported claims that a notable proportion of adolescents who have never smoked have tried an e-cigarette [82]. With the e-cigarette market ever evolving and many devices and liquids developed to be appealing to young people [28], there is a need for longitudinal studies in Northern Ireland to monitor use, due to the risk of nicotine addiction and the possibility of it leading to subsequent smoking of traditional cigarettes $[10,18,20]$.

Phase 2 also provided insights into the personal, social and control beliefs underlying intentions to use e-cigarettes. The TPB has a proven track record for exploring and measuring adolescent smoking behaviour [83-86], thus adding validity to our theoretical approach applied to e-cigarettes. Whilst a small number of recent studies have applied the TPB to e-cigarette use, there are limitations as to what can be drawn from that work, as they have not followed the recommended steps as identified by Ajzen [39] and Francis [40] for the design and conduct of TPB studies [43]. The few that have used the TPB have done so with adult or student populations, with paucity of work conducted amongst adolescents [43-45]. The current research addressed gaps in the literature, and also enabled identification of targets for intervention development, another major strength to this research and application of the TPB.

Holding more positive attitudes about e-cigarettes has recently been found to predict their use in adolescents [76]. The current study lends further support to these findings as the main attitudinal predictors of intentions to use e-cigarettes were more positive in nature, such as e-cigarettes being regarded as more fun to use, cheaper and safer than traditional cigarettes and less likely to get the young people into trouble with their parents, if caught using them. Previous studies have found similar results. Specifically, e-cigarettes have been reported to be a safer and healthier alternative to cigarettes [87, 88], less addictive [89, 90], cheaper and more convenient to use [91, 92]. Whilst there was some awareness of the debate around the health and safety implications in the qualitative aspects of the current study, with some participants describing them as harmful, it was the positive attitudes that predicted intentions to use e-cigarettes, which is in keeping with previous research [76]. As such, education around e-cigarette use is needed to present a more balanced view of e-cigarettes and address potential risks as well as benefits to enhance informed choices around their use.

This seems to be particularly important given that evidence is accumulating to suggest that the use of nicotinebased e-cigarettes in this age group may lead to a nicotine addiction and subsequent uptake of smoking traditional cigarettes [10, 17, 18, 93]. E-cigarettes have been linked to the normalisation and greater acceptance of smoking type behaviours in young people, which could further contribute to the uptake of traditional forms of smoking [10]. In some countries, e-cigarette use in young people has been linked to alcohol and drug use [10, 23, 24]. Although, some of the evidence is US based, and not directly applicable to NI, it does highlight potential issues and the need for monitoring to ensure it does not happen. This coupled with emerging evidence suggesting they have the potential to impact on respiratory, cardiovascular and brain function in adolescents, with short term use [1, 29, 36], makes it more important to address the reason why young people use e-cigarettes in an educational context [38].

In the current study, there was a strong normative influence on young people to use e-cigarettes, especially from friends and family, which also supports pervious work in this area [94]. This is in keeping with the strong peer influence on adolescent smoking, which is well established [95]. This played out in several significant ways. Specifically, the influence of one's friends was the most significant normative predictor of intentions to use e-cigarettes and the encouragement provided by friends was also identified as a significant facilitator. The influence of peer pressure was also apparent in the qualitative data with the young people acknowledging e-cigarette 
use as a social behaviour subjected by peer-pressure, and the need to 'fit in' $[91,96]$. Having parental permission significantly facilitated the use of e-cigarettes in this sample, whilst 'the fear of getting into trouble with one's parents' and 'adhering to the law' were significant inhibitors, similar to previous research [97]. This together with the finding that users were more likely to have parents who used e-cigarettes and who gave their permission to use their devices suggests that parental attitudes and vaping behaviour is significantly associated with e-cigarette use in young people $[98,99]$. Further, parental e-cigarette use, and tobacco smoking was associated with e-cigarette use in young people, as previous studies have found [100, 101]. Of course, this finding has policy implications; and public health authorities need to weigh up the balance between encouraging e-cigarette use by adult smokers and how this might affect uptake in young people.

The influence of control was also apparent in the role played by self-efficacy which was found to be a significant predictor of both current e-cigarette use and intentions to smoke e-cigarettes within the next month. Self-efficacy is important when targeting beliefs to change behaviour, as it is associated with feeling empowered and having control over one's behaviour and the confidence in the choice that one makes and is vital for promoting resistance to potential harmful behaviours [102].

General control belief can be broken down into facilitators and barriers to e-cigarette use. In the current study, the main control beliefs that acted as facilitators were parental permission, curiosity, owning an e-cigarette, friends using e-cigarettes, perceived as being "cool". Those control beliefs that acted as barriers were, getting into trouble with parents and breaking the law. In other words, having friends and parents who smoked e-cigarettes facilitated access, as it provided young people with opportunities to use their devices [72, 87, 103]. This in turn served to enhance their confidence in their ability to use them. Indeed, some people commented if your friends are using them or your parents have one, you can use theirs', see also [7, 104-106]. This appeared to be reinforced by the belief that their parents perceived e-cigarettes as a less harmful alternatives to smoking.

Considering the need for theory driven programmes that focus on e-cigarettes for young people [2, 38], this study identified several targets for intervention by mapping components of the TPB, that predict intentions to use e-cigarettes onto the TDF, to establish intervention functions and appropriate BCTs for inclusion in the framework for educational resource. Of primary importance is holding positive attitudes to e-cigarettes, the role played by one's significant others, particularly one's parents and friends, and the empowering of young people to abstain from using e-cigarettes and reducing accessibility of these products in this age group. A combination of approaches may be employed to achieve these objectives including the use of education, restriction, modelling and environmental restructuring, all used in previous tobacco prevention campaigns $[107,108]$ and in a recent e-cigarette prevention programme [75]. In the context of a framework for an educational resource, similar to the ASSIST intervention in the context of smoking cessation [109], the aim is to develop less favourable attitudes, make e-cigarettes more socially unacceptable for recreational use in young people and promote refusal skills, around the use of e-cigarettes. Such approaches have worked well in other health promotion programmes aimed at tobacco prevention with some information on e-cigarettes [38]. To move this educational resource forward, and in keeping with previous prevention campaigns for smoking and a recent one for e-cigarettes in the US [75], the logistics of the educational resource need to be agreed and coproduced with the RAG and UAG [110, 111], that were part of the current study. A multi-modal approach should be adopted to target schools, pupils and parents [38], to co-produce a resource that is fit for purpose and easily embedded within the curriculum.

\section{Strengths}

The TPB is one of the most widely used theories of behaviour change and has been recognised by the NICE guidelines as good practice for intervention design [41, 42]. One of the theory's main strengths, is its flexibility, as it allows for the inclusion of additional predictor variables such as sociodemographic characteristics, knowledge, and other behaviours, which is how it was used in the current study. The TPB has a proven track record for exploring and measuring adolescent smoking behaviour [83-86], so this adds further validity to this theoretical approach employed in the current study This study provides support for the application of the TPB framework to e-cigarette use in young people, as $64 \%$ of the variance in intentions to use e-cigarettes was explained by all of the TPB constructs, a finding which reiterates previous research $[96,112]$. The importance of these constructs was also assessed in relation to current e-cigarette use (albeit retrospectively), addressing a criticism which is often levied at the TPB [107]. Using the TPB framework, in conjunction with the TDF and the BCTTvs1, enabled identification of appropriate BCTs to target key beliefs around e-cigarette use, in the design of a framework for an educational resource to be used in schools. The educational resource will hopefully help to achieve public health priorities in Northern Ireland. In this jurisdiction, the Public Health Agency recognise that e-cigarettes may have health benefits for smokers but do not regard e-cigarettes as safer than established smoking cessation 
tools and do not advocate for use in young people or as a smoking cessation tool.

\section{Limitations}

The TPB is not without its critics, but no one theoretical framework can explain all variation in behaviour. Its focus on rational reasoning, excluding the influence of unconscious processes that may limit its ability to explain unplanned e-cigarettes use [113]. However, the amount of variance explained in the present context was comparable with previous research, which supports its use with young people [114]. Criticism of the theory has also centred on the use of TPB questionnaires, which are typically long and include the use of outcome expectancy measures, which are often viewed by respondents as somewhat repetitive [62]. This can negatively impact on responding. In order to combat this in the current study, participants' behaviour, during completion was closely monitored; emphasis was given to the importance of honesty and personal opinion. As such, it was stressed that there were no right, or wrong answers and the response formats were varied across the questions to prevent response bias [39]. The sample focused on younger pupils (with an average age of 13 years), due to GCSE commitments in older pupils. Since the study findings suggests that e-cigarette use increased with age; future research should aim to ensure that older pupils are represented. Further, longitudinal evaluative research is needed to determine trajectories of e-cigarette use in adolescents, to establish links to nicotine addiction and links to traditional smoking, as well as co-production and establishing the effectiveness of the educational intervention to prevent uptake in this age group.

\section{Conclusion}

This study has provided a unique opportunity to map the findings against the most well-respected behavioural change frameworks to inform the design of a framework for an educational intervention, which should be of use to key stakeholders in the areas of education and public health interested in reducing the prevalence of e-cigarette use in young people.

This framework addressed the key attitudes, social and control influences that promote e-cigarette use in this cohort, while presenting a balanced approach to facilitate harm reduction and information on cessation of both e-cigarettes and nicotine products. The franework needs to be reviewed and the intervention co-produced and piloted with key stakeholders and young people, to establish where best to place it within the curriculum and to evaluate its effectiveness at informing young people about e-cigarette use.
Abbreviations

TPB: Theory of Planned Behaviour; PHA: Public Health Agency; DOH: Department of Health; UK: United Kingdom; ASH: Action on Smoking and Health; NICE: National Institute for Clinical Excellence; EA: Education Authority; UREC: Ulster University Research Ethics Committee; FSM: Free School Meals; TACT: Target, Action, Context and Time; SN: Subjective Norm; PBC: Perceived Behavioural Control; RAG: Research Advisory Group; UAG: User Advisory Group; SPSS: Statistical Package for the Social Sciences; TDF: Theoretical Domains Framework; APEASE: Affordability, Practicability, Effectiveness Acceptability, Sideeffects/ safety, and Equity; BCTT: Behaviour Change Techniques Taxonomy; BCW: Behaviour Change Wheel; BCT: Behaviour Change Techniques; NISRA: Northern Ireland Research and Statistics Agency; GCSE: General Certificate of Secondary Education.

\section{Supplementary Information}

The online version contains supplementary material available at https://doi. org/10.1186/s12889-022-12674-3.

\section{Additional file 1.}

\section{Acknowledgements}

The Research Advisory Group who comprised members from the following organisations Public Health Agency Northern Ireland, Northern Ireland Chest Heart and Stroke, Institute for Public Health Ireland, HSC R\&D, Cancer Research UK, for their advice and input into the design and implementation of this work. To Prof Linda Bauld University of Edinburgh who supported and advised on the research protocol. To all the schools and pupils who took part in our research.

\section{Authors' contributions}

EEAS was the principal investigator of the study and oversaw all three Phases of the work undertaken, including the writing, and editing of this paper. JDa gathered the data for Phase 1 of the study, analysed, coded, and interpreted the data with the help and support of MMcL. JDo gathered the data for Phase 2 of the study, and alongside EEAS and MG completed the data analyses and write of the results section of the paper. LD advised on the ethical processes required for Phase 1 and Phase 2 and the co-production of the research with RAG and UAG. EEAS, JDo, JDa, MMCL, LD, CMCD, MG all contributed to the design of the research undertaken and revised the manuscript critically for intellectual content. All authors read and approved the final manuscript.

Funding

This research was funded by a grant from Chest Heart and Stroke Northern Ireland.

\section{Availability of data and materials}

The dataset and transcripts are not publicly available due to confidentiality and ethical reasons but could be made available from the corresponding author on reasonable request.

\section{Declarations}

Ethics approval and consent to participate

Ethical approval was obtained from Ulster University Research Ethics Committee (UREC), which is in accordance with The Code of Ethics of the World Medical Association (Declaration of Helsinki). As participants were under 18 years old, therefore informed parental written consent and informed written assent (child assent) was obtained from all participants in both Phases of this study.

\section{Consent for publication}

Not applicable. 


\section{Competing interests}

The authors declare they have no competing interests.

\section{Author details}

${ }^{1}$ School of Psychology, Ulster University, Coleraine, Northern Ireland, UK.

${ }^{2}$ School of Nursing and Midwifery, Queens University of Belfast, Belfast, UK.

Received: 19 May 2021 Accepted: 25 January 2022

Published online: 11 February 2022

\section{References}

1. Kavousi M, Pisinger C, Barthelemy JC, Smedt DD, Koskinas K, Marques-Vidal P, et al. Electronic cigarettes and health with special focus on cardiovascular effects: position paper of the European Association of Preventive Cardiology (EAPC). Eur J Prev Cardiol. 2020;29:2047487320941993. https://doi.org/10.1177/2047487320 941993.

2. Perikleous EP, Steiropoulos P, Paraskakis E, Constantinidis TC, Nena E. E-cigarette use among adolescents: an overview of the literature and future perspectives. Front Public Health. 2018;6:86. https://doi.org/10. 3389/fpubh.2018.00086.

3. Action on Smoking and Health [ASH]. Use of e-cigarettes (vaporisers) among adults in Great Britain 2019. Retrieved from https://ash.org.uk/ wp-content/uploads/2019/09/Use-of-e-cigarettes-among-adults-2019. pdf

4. Lovato C, Watts A, Stead LF. Impact of tobacco advertising and promotion on increasing adolescent smoking behaviours. Cochrane Database Syst Rev. 2011;10:1-43. https://doi.org/10.1002/14651858.CD003439. pub2.

5. PHA (2019) E-cigarette evidence update - patterns and use in adults and young people. Available at https://publichealthmat ters.blog.gov.uk/2019/02/27/e-cigarette-evidence-update-patte rns-and-use-in-adults-and-young-people/

6. DOH. Towards a Smokefree Generation: A Tobacco Control Plan for England; 2017. Available at: assets.publishing.service.gov.uk/government/uploads/system/uploads/attachment_data/file/630217/ Towards_a_Smoke_free_Generation_-_A_Tobacco_Control_Plan_for_ England_2017-2022_2_.pdf

7. Laverty AA, Vamos EP, Filippidis F. Uptake of e cigarettes among a nationally representative cohort of UK children. Tob Prev Cessation. 2018:4:1-15. https://doi.org/10.18332/tpc/89727.

8. Vardavas Cl, Filippidis FT, Agaku IT. Determinants and prevalence of e-cigarette use throughout the European Union: a secondary analysis of 26566 youth and adults from 27 countries. Tob Control. 2015;24(5):442-8. https://doi.org/10.1136/tobaccocontrol-2013-051394.

9. Amin S, Dunn AG, Laranjo L. Social influence in the uptake and use of electronic cigarettes: a systematic review. Am J Prev Med. 2020:58(1):129-41. https://doi.org/10.1016/j.amepre.2019.08.023.

10. Gaiha SM, Halpern-Felsher B. Public health considerations for adolescent initiation of electronic cigarettes. Pediatrics. 2020;145(Supplement 2):S175-80. https://doi.org/10.1542/peds.2019-2056E.

11. Kim M, Popova L, Halpern-Felsher B, Ling PM. Effects of e-cigarette advertisements on adolescents' perceptions of cigarettes. Health Commun. 2019;34(3):290-7. https://doi.org/10.18001/TRS.5.2.1.

12. Kong G, Bold KW, Cavallo DA, Davis DR, Jackson A, Krishnan-Sarin S. Informing the development of adolescent e-cigarette cessation interventions: a qualitative study. Addict Behav. 2021;1(114):106720. https:// doi.org/10.1016/j.addbeh.2020.106720.

13. Han G, Son H. What influences adolescents to continuously use e-cigarettes? Public Health Nurs. 2020;37(4):504-9. https://doi.org/10. 1111/phn.12735.

14. Tsai J, Homa DM, Gentzke AS, Mahoney M, Sharapova SR, Sosnoff CS, et al. Exposure to secondhand smoke among nonsmokers-United States, 1988-2014. Morb Mortal Wkly Rep. 2018;67(48):1342. https://doi. org/10.1016/j.ypmed.2020.106009.

15. Bhatt JM, Ramphul M, Bush A. An update on controversies in e-cigarettes. Paediatr Respir Rev. 2020;26(36):75-86. https://doi.org/10.1016/j. prrv.2020.09.003.
16. Lippert AM. Do adolescent smokers use e-cigarettes to help them quit? The sociodemographic correlates and cessation motivations of US adolescent e-cigarette use. Am J Health Promot. 2015;29(6):374-9. https:// doi.org/10.4278/ajhp.131120-QUAN-595.

17. Aleyan S, Cole A, Qian W, Leatherdale ST. Risky business: a longitudinal study examining cigarette smoking initiation among susceptible and non-susceptible e-cigarette users in Canada. BMJ Open. 2018;8(5):1-7. https://doi.org/10.1136/bmjopen-2017-021080.

18. Berry KM, Fetterman JL, Benjamin EJ, Bhatnagar A, Barrington-Trimis $J$, Leventhal AM, et al. Association of electronic cigarette use with subsequent initiation of tobacco cigarettes in US youths. JAMA Netw Open. 2019;2(2):e187794. https://doi.org/10.1001/jamanetworkopen. 2018.7794.

19. Goldenson NI, Leventhal AM, Stone MD, McConnell RS, BarringtonTrimis JL. Associations of electronic cigarette nicotine concentration with subsequent cigarette smoking and vaping levels in adolescents. JAMA Pediatr. 2017;171(12):1192-9. https://doi.org/10.1001/jamapediat rics.2017.3209.

20. Morean ME, Bold KW, Kong G, Gueorguieva R, Camenga DR, Simon P, et al. Adolescents' awareness of the nicotine strength and e-cigarette status of JUUL e-cigarettes. Drug Alcohol Depend. 2019;1(204):107512. https://doi.org/10.1016/j.drugalcdep.2019.05.032.

21. Watkins SL, Glantz SA, Chaffee BW. Association of noncigarette tobacco product use with future cigarette smoking among youth in the population assessment of tobacco and health (PATH) study, 2013-2015. JAMA Pediatr. 2018;172(2):181-7. https://doi.org/10.1001/jamapediatrics.2017. 4173.

22. Wills TA, Sargent JD, Knight R, Pagano I, Gibbons FX. E-cigarette use and willingness to smoke: a sample of adolescent non-smokers. Tob Control. 2016;25(e1):e52-9. https://doi.org/10.1136/tobaccocon trol-2015-052349.

23. Mehra VM, Keethakumar A, Bohr YM, Abdullah P, Tamim H. The association between alcohol, marijuana, illegal drug use and current use of E-cigarette among youth and young adults in Canada: results from Canadian tobacco, alcohol and drugs survey 2017. BMC Public Health. 2019;19(1):1-0. https://doi.org/10.1186/s12889-019-7546-y.

24. Chadi N, Schroeder R, Jensen JW, Levy S. Association between electronic cigarette use and marijuana use among adolescents and young adults: a systematic review and meta-analysis. JAMA pediatrics. 2019:173(10):e192574. https://doi.org/10.1001/jamapediatrics.2019. 2574

25. ASH (2021) response given to an article "Illegal super-strength nicotine vapes disguised as Cadbury's chocolates are being sold to children for $£ 5$ on TikTok so they can be 'smuggled past parents" available at: https://www.dailymail.co.uk/news/article-10068425/Illegal-super-stren gth-nicotine-vapes-disguised-Cadburys-chocolates-sold-TikTok.html.

26. Dawkins L, Cox S, Goniewicz M, McRobbie H, Kimber C, Doig M, et al. 'Real-world'compensatory behaviour with low nicotine concentration e-liquid: subjective effects and nicotine, acrolein and formaldehyde exposure. Addiction. 2018;113(10):1874-82. https://doi.org/10.1111/ add.14271.

27. Duke JC, Lee YO, Kim AE, Watson KA, Arnold KY, Nonnemaker JM, et al. Exposure to electronic cigarette television advertisements among youth and young adults. Pediatrics. 2014;134(1):e29-36. https://doi.org/ 10.1542/peds.2014-0269.

28. Gilley M, Beno S. Vaping implications for children and youth. Curr Opin Pediatr. 2020;32(3):343-8. https://doi.org/10.1097/MOP.0000000000 000889.

29. Overbeek DL, Kass AP, Chiel LE, Boyer EW, Casey AM. A review of toxic effects of electronic cigarettes/vaping in adolescents and young adults. Crit Rev Toxicol. 2020;50(6):531-8. https://doi.org/10.1080/10408444. 2020.1794443

30. Stroup AM, Branstetter SA. Effect of e-cigarette advertisement exposure on intention to use e-cigarettes in adolescents. Addict Behav. 2018;82:1-6. https://doi.org/10.1016/j.addbeh.2018.02.021.

31. Soneji S, Barrington-Trimis JL, Wills TA, Leventhal AM, Unger JB, Gibson $L A$, et al. Association between initial use of e-cigarettes and subsequent cigarette smoking among adolescents and young adults: a systematic review and meta-analysis. JAMA Pediatr. 2017;171(8):788-97. https:// doi.org/10.1001/jamapediatrics.2017.1488 
32. Pisinger C, Døssing M. A systematic review of health effects of electronic cigarettes. Prev Med. 2014;69:248-60. https://doi.org/10.1016/j. ypmed.2014.10.009.

33. Varlet V, Farsalinos K, Augsburger M, Thomas A, Etter JF. Toxicity assessment of refill liquids for electronic cigarettes. Int J Environ Res Public Health. 2015;12(5):4796-815. https://doi.org/10.3390/ijerph120504796.

34. Allen JG, Flanigan SS, LeBlanc M, Vallarino J, MacNaughton P, Stewart $\mathrm{JH}$, et al. Flavoring chemicals in e-cigarettes: diacetyl, 2, 3-pentanedione, and acetoin in a sample of 51 products, including fruit-, candy-, and cocktail-flavored e-cigarettes. Environ Health Perspect. 2016;124(6):733-9. https://doi.org/10.1289/ehp.1510185.

35. Margham J, McAdam K, Forster M, Liu C, Wright C, Mariner D, et al. Chemical composition of aerosol from an e-cigarette: a quantitative comparison with cigarette smoke. Chem Res Toxicol. 2016;29(10):166278. https://doi.org/10.1021/acs.chemrestox.6b00188.

36. Tobore TO. On the potential harmful effects of E-cigarettes (EC) on the developing brain: the relationship between vaping-induced oxidative stress and adolescent/young adults social maladjustment. J Adolesc. 2019;76:202-9. https://doi.org/10.1016/j.adolescence.2019.09.004.

37. Shilco P, Golshan T, Lande S, Nickfardjam K, Roitblat Y, Morgan A, et al. Knowledge and attitudes of adolescents to e-cigarettes: an international prospective study. Int J Adolesc Med Health. 2020:201902010(ahead-of-print). https://doi.org/10.1515/ ijamh-2019-0210.

38. Liu J, Gaiha SM, Halpern-Felsher B. A breath of knowledge: overview of current adolescent E-cigarette prevention and cessation programs. Curr Addict Rep. 2020:1-3. https://doi.org/10.1007/s40429-020-00345-5.

39. Ajzen I. The theory of planned behavior. Organ Behav Hum Decis Process. 1991;50(2):179-211. https://doi.org/10.1016/0749-5978(91) 90020-T.

40. Francis J, Eccles MP, Johnston M, Walker AE, Grimshaw JM, Foy R, et al. Constructing questionnaires based on the theory of planned behaviour: a manual for health services researchers. Newcastle: Centre for Health Services Research; 2004. Available at: https://openaccess.city.ac. uk/id/eprint/1735/1/

41. National Institute for Health and Care Excellence. Behaviour change: general approaches: Public Health Guideline [PH6]. Published: 24 Oct 2007. Available at: https://www.nice.org.uk/guidance/ph6

42. National Institute for Health and Care Excellence. Behaviour change: individual approaches: Public Health Guideline [49]. Published 2 Jan 2014. Available at: https://www.nice.org.uk/guidance/ph49/resources/ behaviour-change-individual-approaches-pdf-1996366337989

43. Case K, Crook B, Lazard A, Mackert M. Formative research to identify perceptions of e-cigarettes in college students: implications for future health communication campaigns. J Am Coll Health. 2016;64(5):380-9. https://doi.org/10.1080/07448481.2016.1158180.

44. Coleman BN, Apelberg BJ, Ambrose BK, Green KM, Choiniere CJ, Bunnell $R$, et al. Association between electronic cigarette use and openness to cigarette smoking among US young adults. Nicotine Tob Res. 2015;17(2):212-8. https://doi.org/10.1093/ntr/ntu211.

45. Scheinfeld E, Crook B, Perry CL. Understanding young Adults'E-cigarette use through the theory of planned behavior. Health Behav Policy Rev. 2019;6(2):115-27. https://doi.org/10.14485/HBPR.6.2.1.

46. Bauld L, MacKintosh AM, Eastwood B, Ford A, Moore G, Dockrell M, et al. Young people's use of e-cigarettes across the United Kingdom: findings from five surveys 2015-2017. Int J Environ Res Public Health. 2017;14(9):973. https://doi.org/10.3390/ijerph14090973.

47. Tremblay B, Turk MT, Cooper MR, Zoucha R. Knowledge, attitudes, and perceptions of young adults about electronic nicotine delivery Systems in the United States: an integrative review. J Cardiovasc Nurs. 2022:6-97. https://doi.org/10.1097/JCN.0000000000000731.

48. Giles M, Millar S, Armour C, McClenahan C, Mallett J, Stewart-Knox B. Promoting positive attitudes to breastfeeding: the development and evaluation of a theory-based intervention with school children involving a cluster randomised controlled trial. Matern Child Nutr. 2015;11(4):656-72. https://doi.org/10.1111/mcn.12079.

49. Cane J, O'Connor D, Michie S. Validation of the theoretical domains framework for use in behaviour change and implementation research. Implementation Sci. 2012;7(1):37. https://doi.org/10.1186/ 1748-5908-7-37.
50. Michie S, Johnston M, Francis J, Hardeman W, Eccles M. From theory to intervention: mapping theoretically derived behavioural determinants to behaviour change techniques. Appl Psychol. 2008;57(4):660-80. https://doi.org/10.1111/j.1464-0597.2008.00341.x.

51. Hyde A, Howlett E, Brady D, Drennan J. The focus group method: insights from focus group interviews on sexual health with adolescents. Soc Sci Med. 2005;61(12):2588-99. https://doi.org/10.1016/j.socscimed. 2005.04.040.

52. Marks DF, Yardley L, editors. Research methods for clinical and health psychology: Sage; 2004

53. Education Authority for Northern Ireland. Free School Meals 2009. Available at https://www.eani.org.uk/financial-help/free-school-meals

54. Gibson F. Conducting focus groups with children and young people: strategies for success. J Res Nurs. 2007;12(5):473-83. https://doi.org/10. $1177 / 1744987107079791$

55. Fusch PI, Ness LR. Are we there yet? Data saturation in qualitative research. Qual Rep. 2015;20(9):1408-16. https://doi.org/10.46743/21603715/2015.2281.

56. Miles M, Huberman A. Qualitative data analysis: an expanded sourcebook. 2nd ed. Thousand Oaks: Sage Publications; 1994.

57. Hannah DR, Lautsch BA. Counting in qualitative research: why to conduct it, when to avoid it, and when to closet it. J Manag Inq. 2011;20(1):14-22. https://doi.org/10.1177/1056492610375988.

58. Wight $D$, Wimbush $E$, Jepson $R$, Doi L. Six steps in quality intervention development (6SQuID). J Epidemiol Community Health. 2016;70(5):520 5. https://doi.org/10.1136/jech-2015-205952.

59. Kline RB. Principles and practice of structural equation modelling. 3rd ed. New York: Guilford Press; 2010.

60. Cronbach $\sqcup$. Coefficient alpha and the internal structure of tests. Psychometrika. 1951;16(3):297-334. https://doi.org/10.1007/BF02310555.

61. Devoy S, Simpson EEA. Help-seeking intentions for early dementia diagnosis in a sample of Irish adults. Aging Ment Health. 2017;21(8):870-8. https://doi.org/10.1080/13607863.2016.1179262.

62. Giles M, Connor S, McClenahan C, Mallett J, Stewart-Knox B, Wright M. Measuring young people's attitudes to breastfeeding using the theory of planned behaviour. J Public Health. 2007;29(1):17-26. https://doi.org/ 10.1093/pubmed/fdl083.

63. Field A. Discovering statistics using SPSS. 3rd. ed. London: Sage Publications; 2009

64. Tabachnick BG, Fidell LS. Using multivariate statistics. 5th ed. Essex: Pearson Education; 2007.

65. Fishbein M, Ajzen I. Predicting and changing behavior: the reasoned action approach: Psychology press; 2019.

66. Michie S, Abraham C. Advancing the science of behaviour change: a plea for scientific reporting. Addiction. 2008;103(9):1409-10. https://doi. org/10.1111/j.1360-0443.2008.02291.x.

67. Cane J, Richardson M, Johnston M, Ladha R, Michie S. From lists of behaviour change techniques (BCT s) to structured hierarchies: comparison of two methods of developing a hierarchy of BCT s. Br J Health Psychol. 2015;20(1):130-50. https://doi.org/10.1111/bjhp.12102.

68. Atkins L, Francis J, Islam R, O'Connor D, Patey A, Ivers N, et al. A guide to using the theoretical domains framework of behaviour change to investigate implementation problems. Implementation Sci. 2017;12(1):77. https://doi.org/10.1186/s13012-017-0605-9.

69. Michie S, Atkins L, West R. The behaviour change wheel: a guide to designing interventions. UK: Silverback Publishing; 2014.

70. Michie S, Richardson M, Johnston M, Abraham C, Francis J, Hardeman W, et al. The behavior change technique taxonomy ( $v 1)$ of 93 hierarchically clustered techniques: building an international consensus for the reporting of behavior change interventions. Ann Behav Med. 2013;46(1):81-95. https://doi.org/10.1007/s12160-013-9486-6.

71. Connell LE, Carey RN, De Bruin M, Rothman AJ, Johnston M, Kelly MP, et al. Links between behavior change techniques and mechanisms of action: an expert consensus study. Ann Behav Med. 2019;53(8):708-20. https://doi.org/10.1093/abm/kay082.

72. Carey FR, Rogers SM, Cohn EA, Harrell MB, Wilkinson AV, Perry CL. Understanding susceptibility to e-cigarettes: a comprehensive model of risk factors that influence the transition from non-susceptible to susceptible among e-cigarette naïve adolescents. Addict Behav. 2019;91:68-74. https://doi.org/10.1016/j.addbeh.2018.09.002. 
73. Johnston M, Carey RN, Connell Bohlen LE, Johnston DW, Rothman AJ, de Bruin $M$, et al. Development of an online tool for linking behavior change techniques and mechanisms of action based on triangulation of findings from literature synthesis and expert consensus. Transl Behav Med. 2020;11(5);1049-65. https://doi.org/10.1093/tbm/ibaa050.

74. Kelder SH, Mantey DS, Van Dusen D, Case K, Haas A, Springer AE. A middle school program to prevent e-cigarette use: a pilot study of "CATCH my breath". Public Health Rep. 2020;135(2):220-9. https://doi.org/10. 1177/0033354919900887.

75. Kelder SH, Mantey DS, Van Dusen D, Vaughn T, Bianco M, Springer AE. Dissemination of CATCH my breath, a middle school E-cigarette prevention program. Addict Behav. 2021;113:106698. https://doi.org/ 10.1016/j.addbeh.2020.106698.

76. Noar SM, Rohde JA, Prentice-Dunn H, Kresovich A, Hall MG, Brewer NT. Evaluating the actual and perceived effectiveness of e-cigarette prevention advertisements among adolescents. Addict Behav. 2020;109:106473. https://doi.org/10.1016/j.addbeh.2020.106473.

77. Reilly KC. Parents as agents of change in the treatment of childhood obesity and the promotion of Children's health Behaviours.2019 Available at: https://ir.lib.uwo.ca/etd/6052/

78. Northern Ireland research and statistics agency [NISRA]. Young person's behaviours and attitudes survey 2016. Belfast: Department of Health; 2017. Retrieved from https://www.health-ni.gov.uk/articles/youngpersons-behaviour-attitudes-survey

79. Dochrell M. E-cigarette evidence update - patterns of use in adults and young people: PHE; 2019. Available at: https://publichealthmat ters.blog.gov.uk/2019/02/27/e-cigarette-evidence-update-patte rns-and-use-in-adults-and-young-people/

80. McNeill A, Brose L, Calder R, Robson D, Bauld L, Dockrell M. E-cigarette regulation in the United States and the United Kingdom: two countries divided by a common language. Am J Public Health. 2019;109(11):e267. https://doi.org/10.2105/AJPH.2019.305349.

81. Brown R, Van Godwin J, Copeland L, Hallingberg B, Angel L, MacDonald $S$, et al. Ecological exploration of knowledge and attitudes towards tobacco and E-cigarettes among primary school children, teachers, and parents in Wales: a qualitative study. Tobacco Use Insights. 2020;13, 1-12. https://doi.org/10.1177/1179173X20938770.

82. Chapman SL, Wu LT. E-cigarette prevalence and correlates of use among adolescents versus adults: a review and comparison. J Psychiatr Res. 2014;54:43-54. https://doi.org/10.1016/j.jpsychires.2014.03.005.

83. Guo Q, Unger JB, Azen SP, MacKinnon DP, Johnson CA. Do cognitive attributions for smoking predict subsequent smoking development? Addict Behav. 2012;37(3):273-9 [Cited 2019 Oct 11]. Available from: http://www.ncbi.nlm.nih.gov/pubmed/22112425 pmid:22112425.

84. McMillan B, Higgins AR, Conner M. Using an extended theory of planned behaviour to understand smoking amongst schoolchildren. Addict Res Theory. 2005;13(3):293-306. https://doi.org/10.1080/16066 350500053679.

85. Moan IS, Rise J. Predicting smoking reduction among adolescents using an extended version of the theory of planned behaviour. Psychol Health. 2006;21(6):717-38. https://doi.org/10.1080/147683206006034 48.

86. Zhao X, White KM, MCD YR. A TPB-based smoking intervention among Chinese high school students. Subst Use Misuse. 2019;54(3):459-72. https://doi.org/10.1080/10826084.2018.1508298.

87. Nicksic NE, Barnes AJ. Is susceptibility to E-cigarettes among youth associated with tobacco and other substance use behaviors one year later? Results from the PATH study. Prev Med. 2019;121:109-14. https:// doi.org/10.1016/j.ypmed.2019.02.006.

88. Filippidis FT, Laverty AA, Mons U, Jimenez-Ruiz C, Vardavas Cl. Changes in smoking cessation assistance in the European Union between 2012 and 2017: pharmacotherapy versus counselling versus e-cigarettes. Tob Control. 2019;28(1):95-100. https://doi.org/10.1136/tobaccocon trol-2017-054117.

89. Fulton E, Gokal K, Griffiths S, Wild S. More than half of adolescent E-cigarette users had never smoked a cigarette: findings from a study of school children in the UK. Public Health. 2018;161:33-5. https://doi.org/ 10.1016/j.puhe.2018.04.014.

90. Logue JM, Sleiman M, Montesinos VN, Russell ML, Litter MI, Benowitz $\mathrm{NL}$, et al. Emissions from electronic cigarettes: assessing vapers' intake of toxic compounds, secondhand exposures, and the associated health impacts. Environ Sci Technol. 2017;51(16):9271-9. https://doi.org/10. 1021/acs.est.7b00710.

91. Pokhrel P, Herzog TA, Muranaka N, Fagan P. Young adult e-cigarette users' reasons for liking and not liking e-cigarettes: a qualitative study. Psychol Health. 2015;30(12):1450-69. https://doi.org/10.1080/08870 446.2015.1061129.

92. Measham F, O'Brien K, Turnbull G. "Skittles \& red Bull is my favourite flavour": E-cigarettes, smoking, vaping and the changing landscape of nicotine consumption amongst British teenagers-implications for the normalisation debate. Drug Educ Prev Polic. 2016;23(3):224-37. https:// doi.org/10.1080/09687637.2016.1178708.

93. Wills TA, Sargent JD, Gibbons FX, Pagano I, Schweitzer R. E-cigarette use is differentially related to smoking onset among lower risk adolescents. Tob Control. 2017;26(5):534-9. https://doi.org/10.1136/tobaccocon trol-2016-053116.

94. McKeganey N, Barnard M. Change and continuity in vaping and smoking by young people: a qualitative case study of a friendship group. Int J Environ Res Public Health. 2018;15(5):1008. https://doi.org/10.3390/ ijerph15051008.

95. Hoffman BR, Sussman S, Unger JB, Valente TW. Peer influences on adolescent cigarette smoking: a theoretical review of the literature. Subst Use Misuse. 2006;41(1):103-55. https://doi.org/10.1080/1082608050 0368892.

96. Hershberger A, Connors M, Um M, Cyders MA. The theory of planned behavior and e-cig use: impulsive personality, e-cig attitudes, and e-cig use. Int J Ment Health Addict. 2018;16(2):366-76. https://doi.org/10. 1007/s11469-017-9783-6.

97. Akre C, Suris JC. Adolescents and young adults' perceptions of electronic cigarettes as a gateway to smoking: a qualitative study in Switzerland. Health Educ Res. 2017;32(5):448-54. https://doi.org/10. 1093/her/cyx054.

98. Alves J, Perelman J, Soto-Rojas V, Richter M, Rimpelä A, Loureiro I, et al. The role of parental smoking on adolescent smoking and its social patterning: a cross-sectional survey in six European cities. J Public Health. 2017;39(2):339-46. https://doi.org/10.1093/pubmed/fdw040.

99. Bold KW, Kong G, Cavallo DA, Camenga DR, Krishnan-Sarin S. Reasons for trying e-cigarettes and risk of continued use. Pediatrics. 2016;138(3):e20160895. https://doi.org/10.1542/peds.2016-0895.

100. Fite PJ, Cushing CC, Poquiz J, Frazer AL. Family influences on the use of e-cigarettes. J Substance Use. 2018;23(4):396-401. https://doi.org/10. 1080/14659891.2018.1436601.

101. Notley C, Ward E, Dawkins L, Holland R. The unique contribution of e-cigarettes for tobacco harm reduction in supporting smoking relapse prevention. Harm Reduct J. 2018;15(1):31. https://doi.org/10.1186/ s12954-018-0237-7.

102. Burke NJ, Bird JA, Clark MA, Rakowski W, Guerra C, Barker JC, et al. Social and cultural meanings of self-efficacy. Health Educ Behav. 2009;36(5_ suppl):111S-28S. https://doi.org/10.1177/1090198109338916.

103. Thrul J, Gubner NR, Tice CL, Lisha NE, Ling PM. Young adults report increased pleasure from using e-cigarettes and smoking tobacco cigarettes when drinking alcohol. Addict Behav. 2019;93:135-40. https:// doi.org/10.1016/j.addbeh.2019.01.011.

104. Barnett TE, Soule EK, Forrest JR, Porter L, Tomar SL. Adolescent electronic cigarette use: associations with conventional cigarette and hookah smoking. Am J Prev Med. 2015;49(2):199-206. https://doi.org/ 10.1016/j.amepre.2015.02.013.

105. Barrington-Trimis JL, Urman R, Berhane K, Unger JB, Cruz TB, Pentz MA, et al. E-cigarettes and future cigarette use. Pediatrics. 2016;138:e20160379. https://doi.org/10.1542/peds.2016-0379.

106. Corsi DJ, Lippert AM. An examination of the shift in school-level clustering of US adolescent electronic cigarette use and its multilevel correlates, 2011-2013. Health Place. 2016;38:30-8. https://doi.org/10. 1016/j.healthplace.2015.12.007.

107. Sheeran P,Webb TL. The intention-behavior gap. Soc Personal Psychol Compass. 2016;10(9):503-18. https://doi.org/10.1111/spc3.12265.

108. Wiehe SE, Garrison MM, Christakis DA, Ebel BE, Rivara FP. A systematic review of school-based smoking prevention trials with long-term follow-up. J Adolesc Health. 2005;36(3):162-9. https://doi.org/10.1016/j. jadohealth.2004.12.003.

109. Campbell R, Starkey F, Holliday J, Audrey S, Bloor M, Parry-Langdon $\mathrm{N}$, et al. An informal school-based peer-led intervention for smoking 
prevention in adolescence (ASSIST): a cluster randomised trial. Lancet. 2008;371 (9624):1595-602. https://doi.org/10.1016/S0140-6736(08) 60692-3.

110. Hawe P. Lessons from complex interventions to improve health. Annu Rev Public Health. 2015;18:36. https://doi.org/10.1146/annurev-publh ealth-031912-114421.

111. NIHR (2019). National Institute for Health Research: guidance on coproduction in a research project. Available at: https://www.invo.org.uk > Copro_Guidance_Feb19.

112. Trumbo CW, Kim S. The effect of electronic cigarette advertising on intended use among college students. Addict Behav. 2015;46:77-81. https://doi.org/10.1016/j.addbeh.2015.03.005.

113. Bold KW, Morean ME, Kong G, Simon P, Camenga DR, Cavallo DA, et al. Early age of e-cigarette use onset mediates the association between impulsivity and e-cigarette use frequency in youth. Drug Alcohol Depend. 2017;181:146-51. https://doi.org/10.1016/j.drugalcdep.2017. 09.025.

114. McEachan RR, Conner M, Taylor NJ, Lawton RJ. Prospective prediction of health-related behaviours with the theory of planned behaviour: a meta-analysis. Health Psychol Rev. 2011;5(2):97-144. https://doi.org/10. 1080/17437199.2010.521684.

\section{Publisher's Note}

Springer Nature remains neutral with regard to jurisdictional claims in published maps and institutional affiliations.

- fast, convenient online submission

- thorough peer review by experienced researchers in your field

- rapid publication on acceptance

- support for research data, including large and complex data types

- gold Open Access which fosters wider collaboration and increased citations

- maximum visibility for your research: over $100 \mathrm{M}$ website views per year

At BMC, research is always in progress.

Learn more biomedcentral.com/submissions 